\title{
The fire toxicity of polyurethane foams
}

\section{(1) CrossMark}

\author{
Sean Thomas McKenna and Terence Richard Hull
}

\begin{abstract}
Polyurethane is widely used, with its two major applications, soft furnishings and insulation, having low thermal inertia, and hence enhanced flammability. In addition to their flammability, polyurethanes form carbon monoxide, hydrogen cyanide and other toxic products on decomposition and combustion.

The chemistry of polyurethane foams and their thermal decomposition are discussed in order to assess the relationship between the chemical and physical composition of the foam and the toxic products generated during their decomposition. The toxic product generation during flaming combustion of polyurethane foams is reviewed, in order to relate the yields of toxic products and the overall fire toxicity to the fire conditions. The methods of assessment of fire toxicity are outlined in order to understand how the fire toxicity of polyurethane foams may be quantified. In particular, the ventilation condition has a critical effect on the yield of the two major asphyxiants, carbon monoxide and hydrogen cyanide.
\end{abstract}

Keywords: Fire, Combustion, Toxic, Toxicity, Polyurethane, Foam, Decomposition, Asphyxiant, Cyanide, HCN

\section{Introduction}

Polyurethanes are a diverse family of synthetic polymers that were first synthesised in 1937 by Otto Bayer. Their development continued commercially in Germany, eventually leading to a global multibillion dollar industry (Vilar 2002). The polyurethane market was estimated to be worth $\$ 33$ billion in 2010 and is expected to continue to grow to over $\$ 55$ billion by 2016 . Global usage is expected to expand from $13.65 \mathrm{Mt}$ in 2010 to $17.95 \mathrm{Mt}$ by 2016. $95 \%$ of the demand for polyurethanes is situated in North America, Asian-pacific, and European markets; with demand expected to increase in Eastern Europe and South America in the next 10-15 years. The two main market uses for polyurethane are in the furniture and interior industry and the construction industry with $28 \%$ and $25 \%$ of the market, respectively (Markets \& Markets report 2011).

\section{Polyurethane chemistry \\ Functional groups}

Polyurethanes are named from the presence of the urethane (also known as carbamate) functional group (Fig. 1). Despite their name, the term polyurethane is used to describe a family of polymers whose monomers

\footnotetext{
* Correspondence: TRHull@uclan.ac.uk

Centre for Fire and Hazard Science, University of Central Lancashire, Preston PR1 2HE, UK
}

\section{Springer Open}

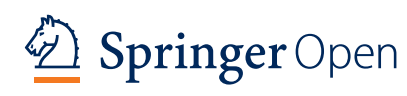

are joined by a range of functional groups primarily derived from the polyaddition of polyisocyanates and polyalcohols. Further reactions occur with amines, water, ureas, urethanes and even other isocyanates to produce a diverse range of functional groups including urethanes, ureas, isocyanurates, carbodiimides and uretdiones. A summary of these structures is shown in Fig. 2 (Avar et al. 2012). This range of functional groups and their ratios in the polymer are a large contributing factor to the wide range of properties that polyurethane materials can possess.

\section{Cross-linking functional groups}

Synthetic polymeric materials may be divided into thermoplastics and thermosets. Thermoplastics are composed of linear polymer molecules, whose shape can be changed repeatedly on heating and which may be melted and solidified without chemical change. Thermosets are cross-linked polymer molecules which, on heating, do not melt but will eventually decompose. Most polyurethanes are cross-linked to some degree and decompose without melting. In addition to the more common process of adding cross-linking reagents during the production process, cross-linkages in polyurethanes can be the result of the high reactivity of the isocyanate precursors. These isocyanate derived cross-links can include biurets and 


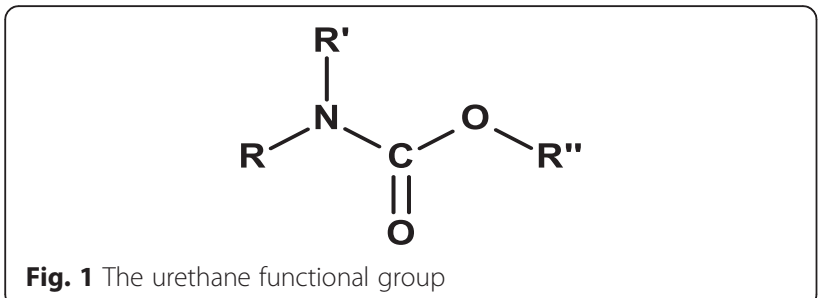

Fig. 1 The urethane functional group

allophanates (Fig. 3) (Aneja 2002). Biurets are the result of the reaction of isocyanates with substitutedurea functional groups and allophanates are formed in small amounts (unless catalysed) by the reaction of isocyanates with urethanes. Additionally, the selfaddition of isocyanates to produce isocyanurates ( $\mathrm{v}$ in Fig. 2), also results in cross-linking in the polymer. Appropriate formulation affords a degree of control over the cross-linking in the polymer without the need for additional cross-linking agents.

\section{Polymerisation reaction}

Isocyanates are a highly reactive family of compounds that are characterised by the $\mathrm{R}-\mathrm{N}=\mathrm{C}=\mathrm{O}$ functional group (where $\mathrm{R}$ can be any aliphatic or aromatic functionality). The strain of two electronegative atoms $(\mathrm{N}$ and $\mathrm{O}$ ) results in electron density being pulled away from the carbon atom, giving it a strong partial positive charge. This makes the isocyanate functional group highly reactive towards nucleophiles with an available hydrogen. These nucleophiles include amines, alcohols, carboxylic acids, thiols, water, ureas and urethanes (Aneja 2002).<smiles>[R]N(C)C(=O)O[Tl]</smiles>

(i)

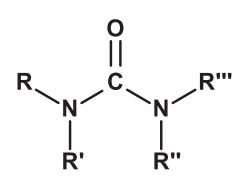

(ii)<smiles>[R]N=C=N[R]</smiles>

(iii)<smiles>[R]N1C(=O)N([R])C1=O</smiles>

(iv)<smiles>[R]n1c(=O)n([R])c(=O)n([R])c1=O</smiles>

(v)
Fig. 2 Common polyurethane functional groups i) urethane ii) urea iii) carbodiimide iv) uretdione $\mathbf{v}$ ) isocyanurate<smiles>[R]NC(=O)N([R])C(=O)N([R7])[R]</smiles>

(i)<smiles>[R]OC(=O)N([R])C(=O)N([R7])[R]</smiles>

(ii)
Fig. 3 Isocyanate derived functional groups that cross-link polyurethane chains i) biurets ii) allophanates

During polymerisation, isocyanates undergo a number of distinct reactions. Primarily, isocyanates react with alcohols to produce urethane linkages in the polymer (Scheme 1). The reaction of an isocyanate functional group with water (Scheme 2) results in the formation of an unstable carbamic acid group, which in turn decomposes to release an amine and carbon dioxide. This amine may then undergo further reaction with other isocyanates present to produce a urea (Scheme 3). The carbon dioxide release by the reaction in Scheme 2 can act as a blowing agent in polyurethane foam production and up to a point the amount of water added will be inversely proportional to the density of the foam. The resulting substituted urea can then react with another isocyanate to produce a biuret linkage (Scheme 4). The reaction of a urethane with another isocyanate will produce an allophanate (Scheme 5).

Isocyanates also react with themselves in various ways to produce dimers, trimers and completely new functional groups. The dimerisation of two isocyanates is a reversible reaction that produces uretidione ring (Scheme 6). The trimerisation results in a highly stable isocyanurate ring which confer additional thermal stability to polyisocyanurates (Scheme 7). Carbodiimides are produced by the reaction of isocyanates in the presence of a catalyst (such as phospholine oxides) (Scheme 8) (Avar et al. 2012).

These reactions make up the basis of polyurethane chemistry and can be used to tailor polyurethanes with a range of properties by varying the structure and ratios of the individual components.

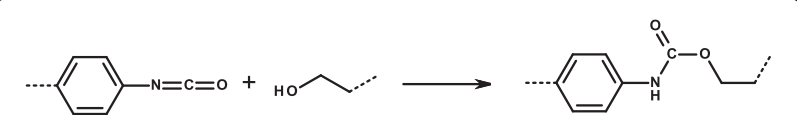

Scheme 1 Reaction between an isocyanate and an alcohol to produce a urethane 


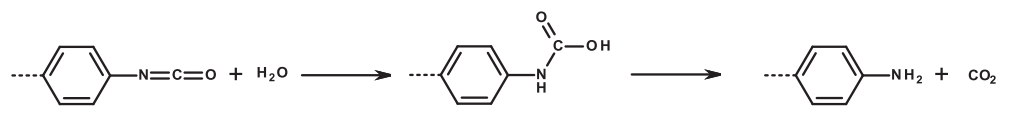

Scheme 2 Reaction of an isocyanate with water to produce a carbamic acid which decomposes to produce an amine and carbon dioxide

\section{Isocyanate reactivity}

The reactivity of isocyanates with the various functional groups commonly present in the production of polyurethanes is dependent on both the steric and electronic factors of the R-group, and also the specific functional group the isocyanate is reacting with. Table 1 shows the relative reactivity of isocyanates with nucleophiles at $25{ }^{\circ} \mathrm{C}$ without the presence of a catalyst. This shows that the reactions of isocyanates are much faster with amines and slower with carboxylic acids, urethanes and amides than for the alcohols used in polyurethane production. An understanding of the relative reaction rates is vital in controlling the production of the polymer and producing the desired physical properties (Herrington \& Hock 1998). In this case, the main reason for including isocyanate reactivity data is to explain the reactivity of isocyanates that are released into fire effluent during combustion. Their apparently transient nature results from their very high reactivity with amines and their fairly high reactivity with water (which is almost always present in fire effluent). The presence of both amines and water in the decomposition products of polyurethane foams are discussed in later sections.

Isocyanate structure also affects the reactivity of the isocyanate group. Bulky substituents that impinge on the isocyanate group can reduce its reactivity. Aromatic isocyanates are more reactive than aliphatic isocyanates due to the electronic effects of the aromatic ring. Substituted aromatics containing electron withdrawing groups further increase the reactivity of isocyanates by increasing the partial positive charge on the isocyanate carbon via a resonance withdrawing effect.

Aromatic diisocyanates, which are commonly used in the production of polyurethanes, have a slightly more complicated chemistry compared to monoiscyanates due to the electronic effects of two isocyanate groups. Aromatic diisocyanates ortho- or para- to one another will have an activating effect on each other, thus increasing their reactivity. However, once one of the groups forms a urethane or urea, the activating effect on the other isocyanate is reduced, as ureas and urethanes are weaker activating groups than isocyanates. Additionally, aromatic isocyanates with more steric hindrance are likely to be less reactive (such as the 2 position in 2,4-TDI (Fig. 4)). This steric hindrance can be offset by increasing the temperature of the reaction or by performing the reaction in the presence of a catalyst (Vilar 2002).

\section{Isocyanate precursors}

The isocyanate precursors used in the production of polyurethane foams usually consist of aromatic diisocyanates such as toluene diisocyanate (TDI) and methylene diphenyl diisocyanate (MDI). Over $90 \%$ of all industrial polyurethanes are based on either TDI or MDI (Avar et al. 2012).

TDI is produced as the 2,4- and the 2,6- isomer which have a boiling point of $121{ }^{\circ} \mathrm{C}$ and $120^{\circ} \mathrm{C}$ respectively. It is usually used in isomeric mixtures of varying ratios, with $80: 202,4$ to 2,6 being the most commonly used (Fig. 4). TDI is primarily used in the production of flexible foams, which are used in the furniture and interior industries.

MDI is a diaromatic diisocyanate compound that boils at $208{ }^{\circ} \mathrm{C}$ and is primarily used in the production of rigid foams. Most rigid foams and speciality polyurethanes use polymeric MDI derivatives which are mixtures components such as dimers and trimers (Fig. 5). Rigid MDI based foams are primarily used for insulation in the construction industry and can also be found in the transport industry.

Other common diisocynates include hexamethylene diisocyanate (HDI), 1,5-naphthalene diisocyanate (NDI) and isophorone diisocyanate (IPDI) (Fig. 6).

\section{Polyol precursors}

As the main reactive group that isocyanates react with, polyols are a major component of the resulting polyurethane product. The two main families of polyols used are polyether polyols and polyester polyols (Fig. 7) (Avar et al. 2012). Polyether polyols are more resistant to hydrolysis, but less stable to oxidation, while for polyester polyols it is the opposite. As polyols are prepolymers, their molecular mass is relevant to their application, with flexible foams being derived from 1000 to 6000 daltons and few hydroxyl groups, while those used in rigid foams have short chains from 250 to 1000 daltons with high functionality (3-12 hydroxyl groups per chain).

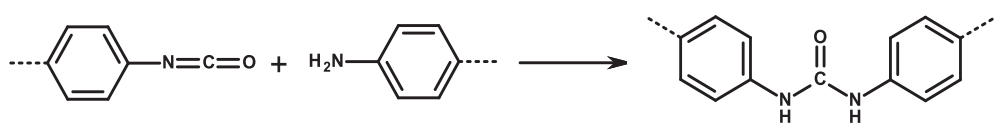

Scheme $\mathbf{3}$ Reaction of an isocyanate with an amine to produce a urea 


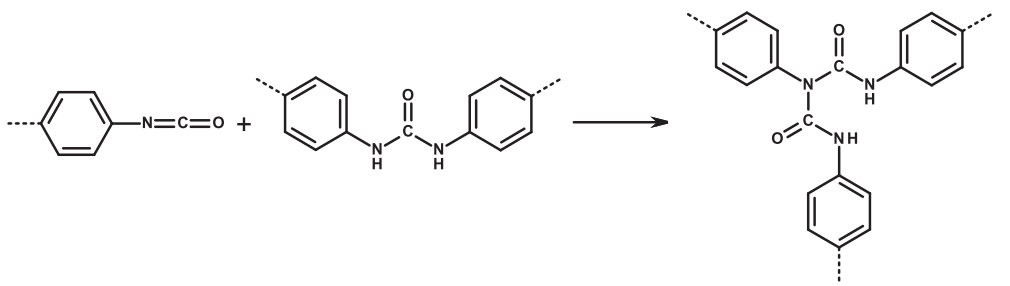

Scheme 4 Reaction of an isocyanate with a urea to produce a biuret linkage

Short chains with high functionality results in highly cross-linked polyurethane polymers which is characteristic of rigid foams.

\section{Thermal decomposition}

\section{Inert-atmosphere}

It is generally accepted that the thermal decomposition occurring during flaming combustion is best represented by the thermal decomposition of a material in an inert atmosphere. This is due to the concentration of oxygen directly under a flame being close or equal to $0 \%$ (Schartel \& Hull 2007). A large number of studies have been performed over the last 50 years to understand the thermal decomposition of polyurethane materials, and as a result of this the mechanism of their decomposition in inertatmospheres is fairly well understood.

\section{Bond stability}

The heating of polyurethanes in an inert-atmosphere results in the progressive rupturing of bonds as a function of temperature. Biuret and allophanate bonds will decompose first between 100 and $125^{\circ} \mathrm{C}$. Ureas and urethanes decompose between 160 and $200{ }^{\circ} \mathrm{C}$. Substituted ureas decompose between 235 and $250{ }^{\circ} \mathrm{C}$ and carbodiimides decompose between 250 and $280^{\circ} \mathrm{C}$. Isocyanurate rings are the most thermally stable in an inert atmosphere and decompose between 270 and $300{ }^{\circ} \mathrm{C}$. A summary of the bond decomposition temperatures in polyurethanes is shown in Table 2 (Gharehbagh \& Ahmadi 2012). Although these temperatures can provide a good general idea of which bonds will be likely to break down with heating, the steric and electronic effects of the attached groups can affect the strength of the bonds and thus the temperature at which the bond will decompose.

\section{Regeneration of Precursors}

Thermal decomposition of polyurethanes is usually the reverse of polymerisation, resulting in the formation their precursor functional compounds-diisocyanates, diamines and dihydroxy compounds. Therefore, the products of decomposition can be predicted from the composition of the polymer. These processes occur at around $300{ }^{\circ} \mathrm{C}$ with the precursor chemicals including TDI, MDI, HDI, polyols (both polyether and polyesterpolyols) and aromatic amines.

Early work by Woolley et al (1975) indicated that the decomposition of polyurethanes up to around $600{ }^{\circ} \mathrm{C}$ resulted in the volatilisation of fragmented polyurethane and subsequent release into a nitrogen rich 'yellow smoke', containing partially polymerised isocyanates and droplets of isocyanate from the foam. Higher temperatures resulted in the volatilisation of most of the polyurethane precursors via the formation of lower molecular weight compounds.

Chambers et al. (1981) reported similar data by analysing the inert-atmosphere pyrolysis of a series of biscarbamates to act as model compounds representing polyurethane foams. At $300{ }^{\circ} \mathrm{C}$, free isocyanates and alcohols were produced from the decomposition of these biscarbamates. At this temperature around one third of the compounds mass was lost as volatile products, and the regenerated alcohol products were mainly present in the residue of the sample. Again, above $600{ }^{\circ} \mathrm{C}$ the compound and any "yellow smoke" present was decomposed into smaller volatile fragments. The study also suggested that any remaining isocyanates residue would react with themselves to produce polycarbodiimides, thus anchoring the isocyanate precursors in the condensed phase until around $600{ }^{\circ} \mathrm{C}$, where they would fragment. While this may occur to some degree, it is

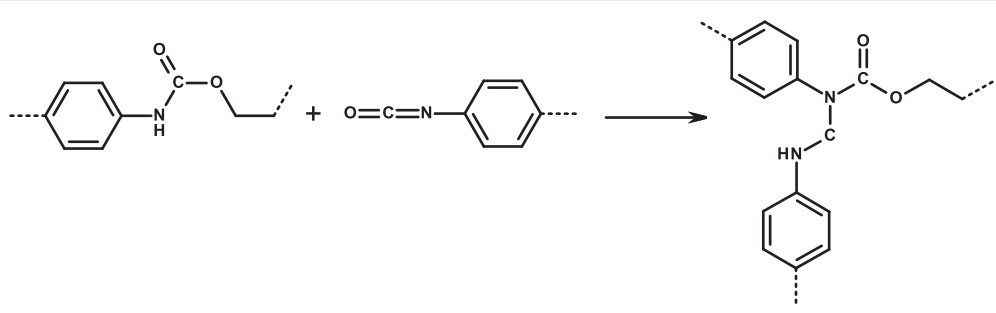

Scheme $\mathbf{5}$ Reaction of a urethane with an isocyanate to produce an allophanate linkage 


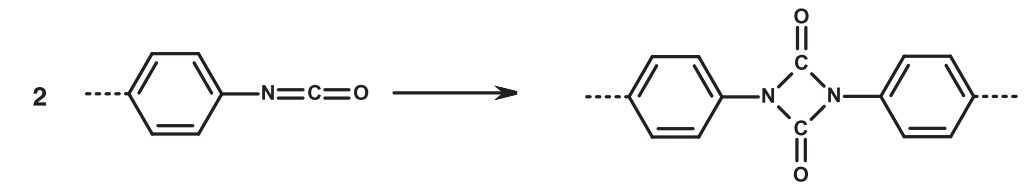

Scheme 6 Self-addition reaction of two isocyanates to produce a uretidione

generally accepted that the majority of the diisocyanates produced in the decomposition of polyurethanes are either volatilised or converted into their amine derivative and then volatilised.

Work by Ravey and Pearce (1997) on the decomposition of a polyether based flexible polyurethane foam suggested that up to $360{ }^{\circ} \mathrm{C}$ the decomposition of the foam was achieved by two main mechanisms. The first being a depolymerisation which would dissociate the polymer to isocyanates and alcohols, the second being dissociation to a primary amine, an olefin and carbon dioxide. The results indicated that the formation of the precursor, TDI, was much faster and preferable to depolymerisation when the volatile compounds could escape. However, when the TDI was unable to enter the pyrolysis zone, the slower, irreversible decomposition to diaminotoluene (DAT) would occur. The authors proposed that once formed, these compounds could partially polymerise with volatilised TDI in the vapour phase to produce Woolley's "yellow smoke". Preliminary calculations suggested that $27 \%$ of the TDI should be recovered as DAT. Experimental data reported a $28 \%$ recovery of DAT which supports the proposed decomposition mechanism.

Recent work by Allan et al. (2013) further supported the presence of two separate decomposition mechanisms for flexible foams. The authors noted a primary depolymerisation of the foam which would release volatile TDI and leave the polyol precursors in the condensed phase. Alongside this, the decomposition of the foam into an amine, alkene and carbon dioxide was also proposed. However, no amines were detected in the vapour phase. Instead polyureas were detected in the vapour phase and also in the condensed phase as a waxy, insoluble white substance. This suggests that any amines formed would have reacted with isocyanates in the vapour phase to form ureas, some of which would have condensed to produce the observed waxy white substance. Subambient differential distillation of the remaining residue yielded a range of short-chain aldehydes (such as formaldehyde and acetaldehyde), ketones, alkenes and high molar mass polyol fragments. The highest concentration these compounds were formed at occurred at a decomposition temperature of $350-400{ }^{\circ} \mathrm{C}$ which indicated no new degradation steps had occurred beyond $350{ }^{\circ} \mathrm{C}$. Additionally, the authors suggested the positions on the polyol chain where bond scission could occur, explaining the presence of the short-chain alkenes, aldehydes and ketones (Scheme 9).

More recent studies have supported and expanded upon the aforementioned thermal decomposition mechanisms of polyurethane foams. Garrido and Font (2015) reported two main steps in the inert-atmosphere decomposition of flexible polyurethane foams. The first step is the decomposition of the urethane bonds to release and volatilise isocyanates up to $300{ }^{\circ} \mathrm{C}$, with long chain alcohols being left behind in the condensed phase, followed by the alcohols degrading at around $400{ }^{\circ} \mathrm{C}$. Isocyanates were primarily produced during the first stage, and in the second stage primarily carbonyls $\left(\mathrm{R}_{2}-\mathrm{C}\right.$ $=\mathrm{O})$ and hydrocarbons were detected using infrared analysis.

The difference in the decomposition of rigid and flexible polyurethane foams was investigated by Chun et al. (2007). They attributed the different decomposition mechanisms to the physical form of the polyurethane

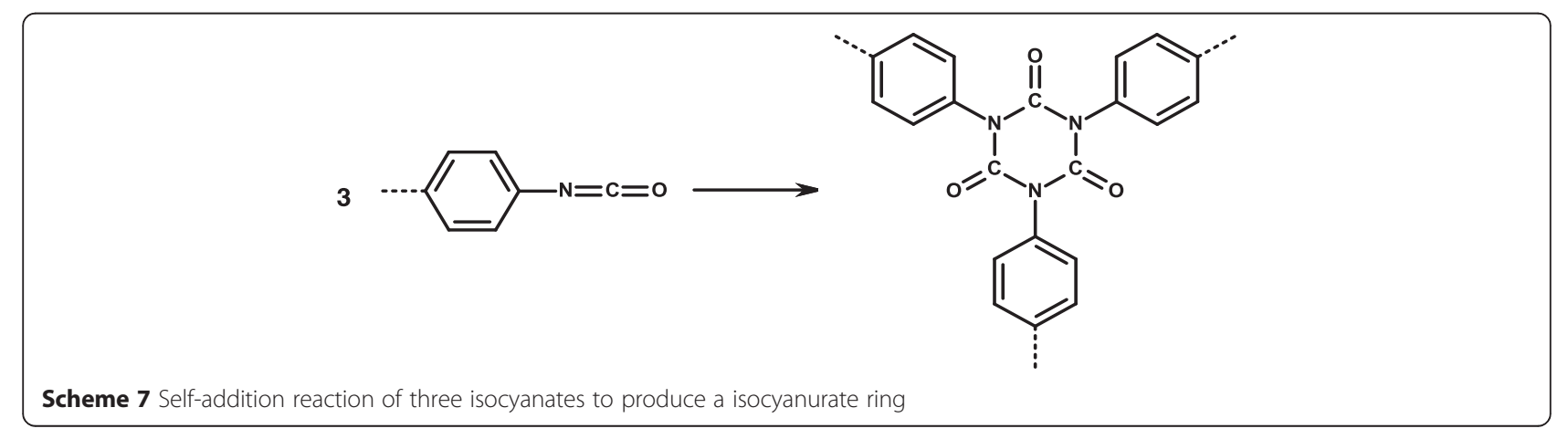




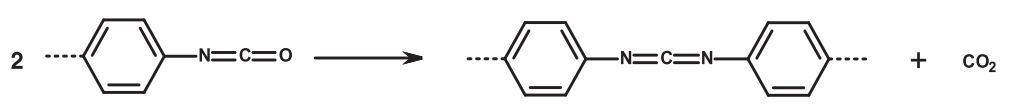

Scheme $\mathbf{8}$ Reaction of two isocyanates to produce a carbodiimide

foam, rather than to any chemical differences. Rigid foam decomposed between 200 and $410{ }^{\circ} \mathrm{C}$, while flexible foam decomposed between 150 to $500{ }^{\circ} \mathrm{C}$. The authors reported GC/MS analysis of the condensed phase products obtained. In both rigid and flexible foams, aniline and $p$-aminotoluene were reported, which correlates with the work of Ravey and Pearce (1997) who reported that isocyanates that did not volatilise were converted into amines in the condensed phase. Rigid polyurethanes primarily produced aromatic compounds in the condensed phase products of decomposition, whereas flexible polyurethanes produced aromatics, alcohols, aldehydes and heterocycles.

\section{High temperature decomposition}

After the initial stages of inert-atmosphere thermal decomposition where the polymer precursors are reformed and volatilised, the decomposition products tend to fragment into smaller molecules. Woolley et al. (1972) noted that the yellow smoke was produced up to around $600{ }^{\circ} \mathrm{C}$, where it would then decompose to give a family of low molecular weight, nitrogen containing products including hydrogen cyanide, acetonitrile, acrylonitrile, pyridine, and benzonitrile. The most notable and abundant of these was hydrogen cyanide which increased in yield from 700 to $1000{ }^{\circ} \mathrm{C}$. At $1000{ }^{\circ} \mathrm{C}$ the hydrogen cyanide produced accounted for a range of between 3.8 and $7.3 \%$ by weight. The authors studied decomposition at $900{ }^{\circ} \mathrm{C}$ of foams, partly decomposed foams, smokes, and pure MDI to assess the hydrogen cyanide ( $\mathrm{HCN})$

Table 1 Relative reactivity of isocyanates with nucleophiles (Herrington \& Hock 1998)

\begin{tabular}{lll}
\hline $\begin{array}{l}\text { Nucleophile with active } \\
\text { hydrogen }\end{array}$ & Structure & $\begin{array}{l}\text { Relative reaction rate } \\
\text { (uncatalysed, 25 }{ }^{\circ} \mathrm{C} \text { ) }\end{array}$ \\
\hline Primary aliphatic amine & $\mathrm{R}-\mathrm{NH}_{2}$ & 100,000 \\
Secondary aliphatic amine & $\mathrm{R}-\mathrm{NH}_{-} \mathrm{R}^{\prime}$ & $20,000-50,000$ \\
Primary aromatic amine & $\mathrm{Ar}^{-\mathrm{NH}_{2}}$ & $200-300$ \\
Primary hydroxyl & $\mathrm{R}-\mathrm{CH}_{2}-\mathrm{OH}$ & 100 \\
Water & $\mathrm{H}_{2} \mathrm{O}$ & 100 \\
Carboxylic acid & $\mathrm{R}-\mathrm{COOH}$ & 40 \\
Secondary hydroxyl & $\mathrm{R}-\mathrm{CH}(\mathrm{OH})-\mathrm{R}^{\prime}$ & 30 \\
Di-urea & $\mathrm{R}-\mathrm{NH}-\mathrm{CO}-\mathrm{NH}-\mathrm{R}^{\prime}$ & 15 \\
Tertiary hydroxyl & $(\mathrm{R})_{3}-\mathrm{C}-\mathrm{OH}$ & 0.5 \\
Urethane & $\mathrm{R}-\mathrm{NH}-\mathrm{COOR}$ & 0.3 \\
Amide & $\mathrm{R}-\mathrm{CONH} \mathrm{H}_{2}$ & 0.1 \\
\hline
\end{tabular}

content and noted that the yields of $\mathrm{HCN}$ were directly related to the nitrogen content. Work published as early as 1959 supported this mechanism of decomposition at higher temperatures and noted that up to $70 \%$ of the nitrogen in the foam could be converted to $\mathrm{HCN}$ at $1000{ }^{\circ} \mathrm{C}$ (Saunders 1959).

The use of ${ }^{13} \mathrm{C}$ labelling by Chambers et al. (1981) on polycarbodiimides and polyureas enabled the determination of the source of the organonitriles and HCN during thermal decomposition. Their analysis indicated that, above $600{ }^{\circ} \mathrm{C}$, the high temperature decomposition of MDI generated a large number of volatile fragments, including benzene, toluene, benzonitrile and toluonitrile. Further fragmentation of these molecules led to the production of $\mathrm{HCN}$, acetonitrile, acrylonitrile and a range of olefinic fragments. The use of ${ }^{13} \mathrm{C}$ labelling in this case allowed the authors to confirm that the nitrogenous compounds, $\mathrm{HCN}$ and organonitriles, originated from the thermal fission of the aromatic rings with the nitrile carbon being the 2-,4- or 6- carbon of the MDI ring.

The production of $\mathrm{HCN}$ and other low molecular weight nitrogenous compounds from the high temperature decomposition of polyurethanes has been reported in the literature in recent years. Work by Guo et al. (2014) on the catalytic decomposition of rigid polyurethane foam waste showed that ammonia, hydrogen cyanide and both nitrogen oxide and nitrogen dioxide were produced at temperatures up to $1100{ }^{\circ} \mathrm{C}$. Additionally, assorted nitrogenous organics were detected in the tar including aniline, quinoline, pyridine, benzonitrile, indole and acridine derivatives with more than $50 \%$ of the tar nitrogen being bound as 4-[(4-aminophenyl)methyl]aniline (the amino analogue of MDI). The detection of the amino MDI derivative in the tar further supports the literature reports of a

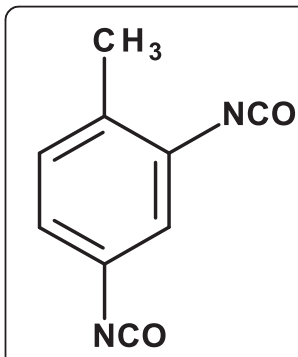

(i)<smiles>Cc1c([N+]=O)cccc1[N+](=O)[O-]</smiles>

(ii)
Fig. 4 2,4-TDI (i) and 2,6-TDI (ii) 


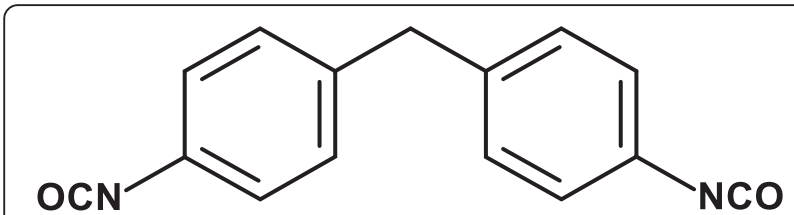

Fig. 5 Methylene diphenyl diisocyanate (MDI)

secondary decomposition mechanism where isocyanates trapped in the condensed phase are converted irreversibly into their amine derivatives.

A review by Paabo and Levin (1987) found that there is no difference in the decomposition products of rigid and flexible polyurethane foams at high temperatures regardless of their differing degradation mechanisms at lower temperatures. Both types of foam yielded very similar products at temperatures above $600{ }^{\circ} \mathrm{C}$.

\section{Oxidative atmosphere}

The non-flaming decomposition of non-fire retarded polyurethane foams in air is generally quite well understood and comparable to the inert atmosphere decomposition, in terms of both products and mechanisms. Investigations by Woolley et al. (1972) suggested that the decomposition was initiated by the release of a nitrogen-rich material at $200-300{ }^{\circ} \mathrm{C}$ which in turn decomposes into low molecular weight nitrogenous fragments above $500{ }^{\circ} \mathrm{C}$. Additionally, a polyol-rich residue is left behind that begins to fragment and volatilise between 300 and $600{ }^{\circ} \mathrm{C}$. The authors noted that the polyester polyols were more stable than the polyether polyols, with the latter fragmenting at a lower temperature $\left(300-400{ }^{\circ} \mathrm{C}\right)$. Further decomposition occurred about $600{ }^{\circ} \mathrm{C}$ with the fragmentation of the "yellow smoke", primarily into hydrogen cyanide and small quantities of acetonitrile, acrylonitrile and benzonitrile. At higher temperatures the decomposition of the foams produced increasing amounts of $\mathrm{HCN}$ from 600 to $900{ }^{\circ} \mathrm{C}$, followed by a sharp rise between $900-1000{ }^{\circ} \mathrm{C}$. The polyester based foam produced nearly double the amount of $\mathrm{HCN}$ between 900 and $1000{ }^{\circ} \mathrm{C}$ than the polyether foam with an increase from $20.8 \mathrm{mg} \mathrm{g}^{-1}$ to $38.0 \mathrm{mg} \mathrm{g}^{-1}$. Similarly, the polyether based foam produced $15.1 \mathrm{mg} \mathrm{g}^{-1}$ to $28.1 \mathrm{mg} \mathrm{g}^{-1}$.

More recent work by Shufen et al. (2006) has supported the claim that polyether based polyurethanes are less stable than their polyester based counterparts when decomposed in air. The polyurethanes used were elastomers based on TDI, which could potentially have differing decomposition mechanisms to their foam counterparts. Thermogravimetric analysis and differential scanning calorimetry (TGA/DSC) showed that the polyether based polyurethane began to decompose at $258{ }^{\circ} \mathrm{C}$, with a second decomposition stage at $350{ }^{\circ} \mathrm{C}$ (which could be attributed to the fragmentation of the polyether polyol). The polyester based polyurethane began to decompose at $284{ }^{\circ} \mathrm{C}$ with a secondary decomposition step at $359{ }^{\circ} \mathrm{C}$. Overall, the results suggested that the polyether based polyurethane was less thermally stable in the presence of oxygen than the polyester, and both were generally less stable in air than in a nitrogen atmosphere.

While several authors work has focused primarily on the nitrogenous products of decomposition, other publications have focused on the production of other compounds such as carbon monoxide. Bott et al. (1969) reported the decomposition of rigid polyurethane foams in both nitrogen and air to assess the production of $\mathrm{CO}$, $\mathrm{HCN}$ and $\mathrm{NH}_{3}$. When a one gram sample of foam was decomposed in air, $\mathrm{CO}$ was formed at a lower temperature than in nitrogen $\left(300{ }^{\circ} \mathrm{C}\right.$ vs $\left.400{ }^{\circ} \mathrm{C}\right)$, with a relative concentration of $5000 \mathrm{ppm}$ at $500{ }^{\circ} \mathrm{C}$. The formation of $\mathrm{HCN}$ was at a higher temperature in both air and nitrogen $\left(400{ }^{\circ} \mathrm{C}\right.$ and $550{ }^{\circ} \mathrm{C}$ respectively) with an average concentration of $200 \mathrm{ppm}$ at $500{ }^{\circ} \mathrm{C}$. The authors suggested that the presence of oxygen does not affect the mechanisms by which $\mathrm{CO}$ and $\mathrm{HCN}$ are produced.

In an attempt to improve the understanding of the thermal decomposition of polyurethanes, Rogaume et al. (2011) developed a mechanism based on both condensed and gas-phase decomposition in air. The authors

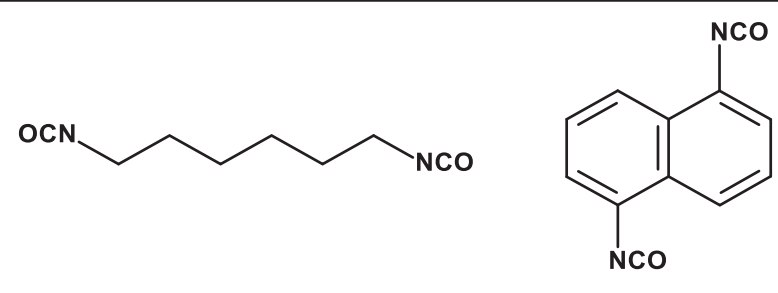

(i) (ii)

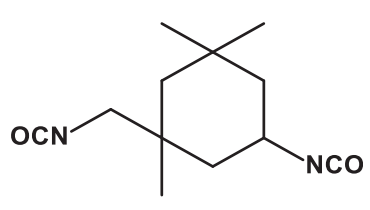

(iii)

Fig. 6 Hexamethylene diisocyanate (HDI) (i), 1,5-naphthalene diisocyanate (NDI) (ii) and isophorone diisocyanate (IPDI) (iii) 


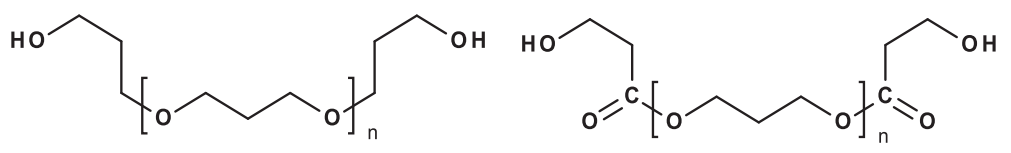

(i)

(ii)

Fig. 7 A polyether polyol (i) and a polyester polyol (ii)

acknowledged the complexity of the decomposition of the material but were able to summarise it effectively in a 5-step mechanism (Fig. 8). The presence of oxygen in the atmosphere directly interacts with the solid phase, which accelerates decomposition. Each of the decomposition steps took place at a lower temperature in air than in nitrogen, which further suggests the direct interaction of oxygen with the foam during decomposition. By using infrared analysis, the authors were able to detect a range of compounds at each step, as summarised in Fig. 8 and Table 3. The results of these experiments and the mechanism of decomposition derived correlated well with work by Rein et al. (2006) and also Garrido and Font (2015).

\section{General decomposition mechanism}

Based on the available literature, the non-flaming decomposition of both rigid and flexible polyurethane foams, in both air and nitrogen, can be generalised into a number of key steps (Fig. 9). The initial decomposition of the foam, at $>300{ }^{\circ} \mathrm{C}$, results in the volatilisation of isocyanates, amines and Woolleys "yellow smoke", leaving behind polyols in the condensed phase. These polyols will fragment and volatilise as the temperature increases, leaving behind a char $\left(>600{ }^{\circ} \mathrm{C}\right)$. This char can decompose further, leaving behind a residue at $>800{ }^{\circ} \mathrm{C}$, to produce simple organic fragments and some polycyclic aromatic hydrocarbons (PAHs). In the gas phase, isocyanates, amines and 'yellow smoke' will begin to decompose at $>600{ }^{\circ} \mathrm{C}$ into low molecular weight nitrogen containing fragments (such as benzonitrile, aniline and hydrogen cyanide $(\mathrm{HCN}))$. At $>800{ }^{\circ} \mathrm{C}$ these compounds further fragment into simple molecules (such as

Table 2 Bond decomposition temperatures of the main polyurethane functional groups (Gharehbagh \& Ahmadi 2012)

\begin{tabular}{ll}
\hline Bond (see Figs. 2 and 3 for structure) & $\begin{array}{l}\text { Decomposition temperature } \\
\text { range } /{ }^{\circ} \mathrm{C}\end{array}$ \\
\hline Allophanate & $100-125$ \\
Biuret & $115-125$ \\
Urea & $160-200$ \\
Urethane & $180-200$ \\
Substituted Urea & $235-250$ \\
Carbodiimide & $250-280$ \\
Isocyanurate & $270-300$ \\
\hline
\end{tabular}

$\mathrm{HCN}, \mathrm{CO}, \mathrm{CH}_{4}$ and $\mathrm{CH}_{2} \mathrm{O}$ ) and PAHs. Polyol fragments in the gas phase will also begin to decompose at $>800{ }^{\circ} \mathrm{C}$ to produce simple organic fragments and PAHs. In air, the resulting decomposition fragments can be oxidised into $\mathrm{CO}, \mathrm{CO}_{2}, \mathrm{H}_{2} \mathrm{O}$ and nitrogen oxides at high temperatures.

These reactions are accelerated in the presence of oxygen, which reduces the temperature of the decomposition steps. Polyurethane foams based on polyether polyols will have a lower decomposition temperature in air than polyester polyol based foams. However, as noted by Paabo and Levin (1987), many studies into the decomposition of polyurethane foams do not differentiate between flaming and non-flaming decomposition, and focus on the temperature of decomposition rather than the presence of flames. Therefore, in certain conditions, polyurethanes foams can reach their auto-ignition temperature and ignite which will significantly alter the effect the decomposition mechanisms and resulting products.

\section{Assessment of fire toxicity}

\section{Yields of toxic products from fires}

Toxic product yields from materials involved in fires depend on a number of factors. Material composition, temperature and oxygen concentration are normally the most important. For the purpose of estimating toxicity in fires, fire growth has been classified into a number of stages (ISO 19706 2011):

1. Smouldering combustion

2. Early well-ventilated flaming

3. Fully-developed under-ventilated flaming

Although on some occasions smouldering (oxidative pyrolysis) can generate toxicologically significant quantities of effluent (for example smouldering cotton, or polyurethane foam), typically the rate of reaction, and hence the amount of toxic species generated will be small, so it is unlikely to affect anyone outside the immediate vicinity. Similarly, well-ventilated fires are generally small, and of low toxicity. As fires grow, they become ventilation controlled, and fires in enclosures such as buildings rapidly change from well-ventilated to under-ventilated. These fires are large, relative to the enclosure, and produce greater volumes of effluent, 

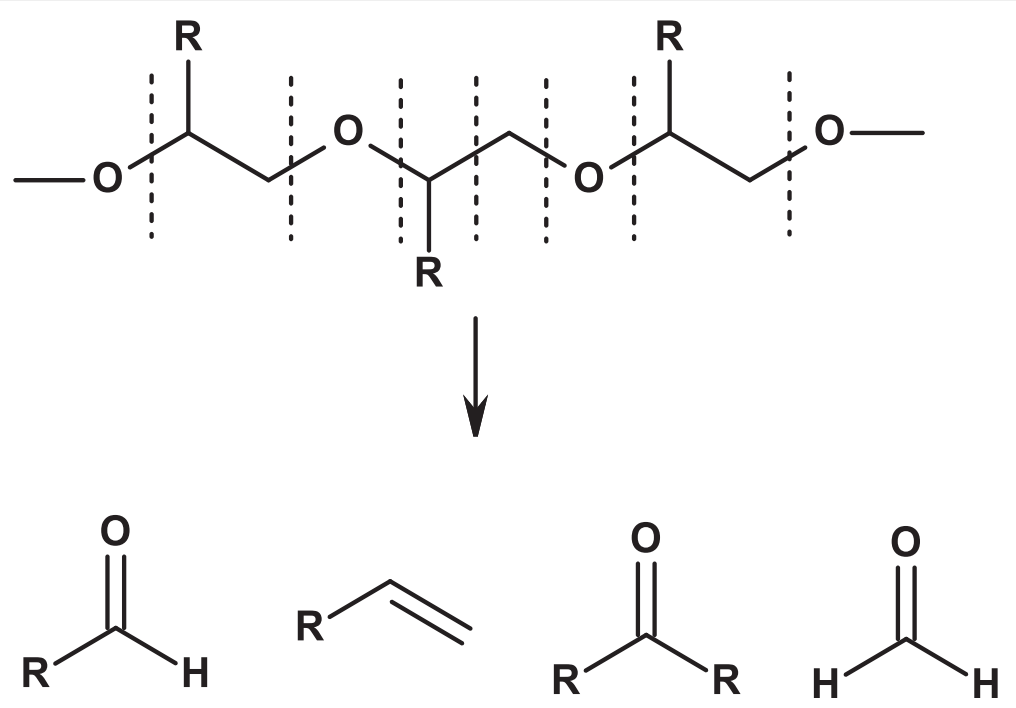

Scheme 9 Suggested points of chain scission on a polyether polyol resulting in aldehydes, ketones and alkenes (Allan et al. 2013)

affecting occupants over a much wider part of any building. While well-ventilated fire scenarios are routinely used for assessment of flammability, because the object is to stop the fire growing to the out of control stage, where fire toxicity is concerned, the important fire stages are under-ventilated. There are two reasons for this:

1. The volume of effluent is much greater.

2. The yields of the major toxic products (carbon monoxide ( $\mathrm{CO}$ ) and hydrogen cyanide ( $\mathrm{HCN}$ ) from $\mathrm{N}$ containing materials) will be much greater.

Almost all unwanted fires are diffusion flames, with inefficient mixing of fuel and oxygen (as opposed to the "premixed" flames found in burner/combustion systems). The interior of large flames are always under-ventilated, because oxygen cannot penetrate the flame. For any larger fire there will always be a significant yield of $\mathrm{CO}, \mathrm{HCN}$ (from nitrogen containing materials), hydrocarbons and smoke.

Data from large scale fires in enclosures, such as a room, shows much higher levels of the two of the major toxicants, carbon monoxide (CO) and hydrogen cyanide (HCN) under conditions of developed flaming (Andersson et al. 2005; Blomqvist \& Lonnermark 2001). It is therefore essential to the assessment of toxic hazard from fire that each fire stage can be adequately replicated, and preferably the individual fire stages treated separately.

\section{Heat, smoke, asphyxiants and irritants}

The toxic hazards associated with fire and the inability of victims to escape from fire atmospheres may be considered in terms of major hazard factors: heat, smoke and toxic combustion products (Hartzell 1993). The time available for escape is the interval between the time of ignition and the time after which conditions become untenable, such that occupants can no longer take effective action to accomplish their own escape. This can result from exposure to radiant and convected heat; visual obscuration due to smoke; inhalation of asphyxiant gases; and exposure to sensory/upper-respiratory irritants. Fire gases contain a mixture of fully oxidised products, such as carbon dioxide $\left(\mathrm{CO}_{2}\right)$, partially oxidised products, such as carbon monoxide $(\mathrm{CO})$ and aldehydes, fuel and fuel degradation products, such as aliphatic or aromatic hydrocarbons, and other stable gas molecules, such as hydrogen halides $(\mathrm{HCl}, \mathrm{HBr})$ and hydrogen cyanide (HCN) (Kaplan et al. 1984a). Heat, smoke and irritant gases may impair escape, increasing the risk of a lethal exposure to asphyxiant gases, and can sometimes lung damage causes death in those managing to escape.

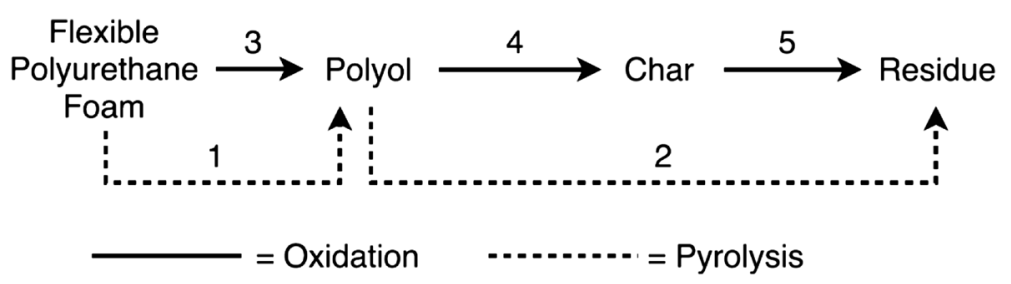

Fig. 8 5-step decomposition mechanism for flexible polyurethane foam (Rogaume et al. 2011) 
Table 3 Products of decomposition of a flexible polyurethane foam based on decomposition steps from Fig. 8 (Rogaume et al. 2011)

\begin{tabular}{lll}
\hline $\begin{array}{l}\text { Decomposition } \\
\text { step }\end{array}$ & Gas phase products & $\begin{array}{l}\text { Condensed phase } \\
\text { products }\end{array}$ \\
\hline 1 & Isocyanates & Polyols \\
2 & Polyol, $\mathrm{CH}_{2} \mathrm{O}, \mathrm{H}_{2} \mathrm{O}$, & Solid residue \\
& $\mathrm{HCN}$ and $\mathrm{CH}_{4}$ & \\
3 & Isocyanates, polyols, & $\begin{array}{l}\text { Mixed polyol and } \\
\text { polyol fragments }\end{array}$ \\
4 & $\mathrm{H}_{2} \mathrm{O}$ and $\mathrm{CO}_{2}$ & Char \\
& $\mathrm{CO}_{2}, \mathrm{CO}_{2} \mathrm{H}_{2} \mathrm{O}, \mathrm{Polyol}$, & \\
$\mathrm{CH}_{2} \mathrm{O}, \mathrm{HCN}$ and $\mathrm{CH}_{4}$ & Residue \\
& $\mathrm{CO}, \mathrm{CO}_{2}, \mathrm{H}_{2} \mathrm{O}, \mathrm{CH}_{2} \mathrm{O}, \mathrm{CH}_{4}$, & \\
& $\mathrm{HCN}$ and small amounts & \\
& of polyol. &
\end{tabular}

The main toxic combustion products can be divided into two classes: asphyxiant gases, which prevent oxygen uptake by cells, with loss of consciousness and ultimately death; and irritant gases which cause immediate incapacitation, mainly by effects on the eyes and upper respiratory tract, and longer term damage deeper in the lung. The effect of asphyxiants and deep lung irritants depend on the accumulated doses, i.e. the sum of each of the concentrations multiplied by the exposure time, for each product; upper respiratory tract irritants are believed to depend on the concentration alone (Purser 2007).

The dangerous concentrations of some important toxic fire gases are shown in Table 4 alongside the influence of ventilation condition on their yields. The yields of acid gases and nitrogen-containing products depend upon the proportion of the appropriate elements in the materials burned and the efficiency of conversion. In general conversion efficiencies are high for halogen acid gases. Most fuel nitrogen is released as $\mathrm{N}_{2}$, but in wellventilated combustion conditions a proportion is released as oxides of nitrogen (mainly NO) and in underventilated combustion conditions a proportion is released as HCN (Purser \& Purser 2008a). CO yields are generally very low for well-ventilated conditions (in the absence of halogens) but increase considerably underventilated combustion conditions. Acrolein and formaldehyde are formed especially from cellulosic materials under non-flaming decomposition conditions, but products of vitiated combustion contain other organic irritants.

\section{Asphyxiant gases}

Asphyxiant or narcotic gases cause a decrease in oxygen supplied to body tissue, resulting in central nervous system depression, with loss of consciousness and ultimately death. The severity of the effects increases with dose (Hartzell 1993). The main asphyxiants, carbon monoxide and hydrogen cyanide have been widely studied and are the best understood (ISO 13571 2007). In addition, asphyxiation can also occur as a result of lowered oxygen concentration, and is affected by the carbon dioxide concentration.

Oxygen depletion can be lethal if the oxygen concentration falls below tenable levels ( $6 \%)$. However, from a fire toxicity perspective it is generally assumed that heat and other gases will have already prevented

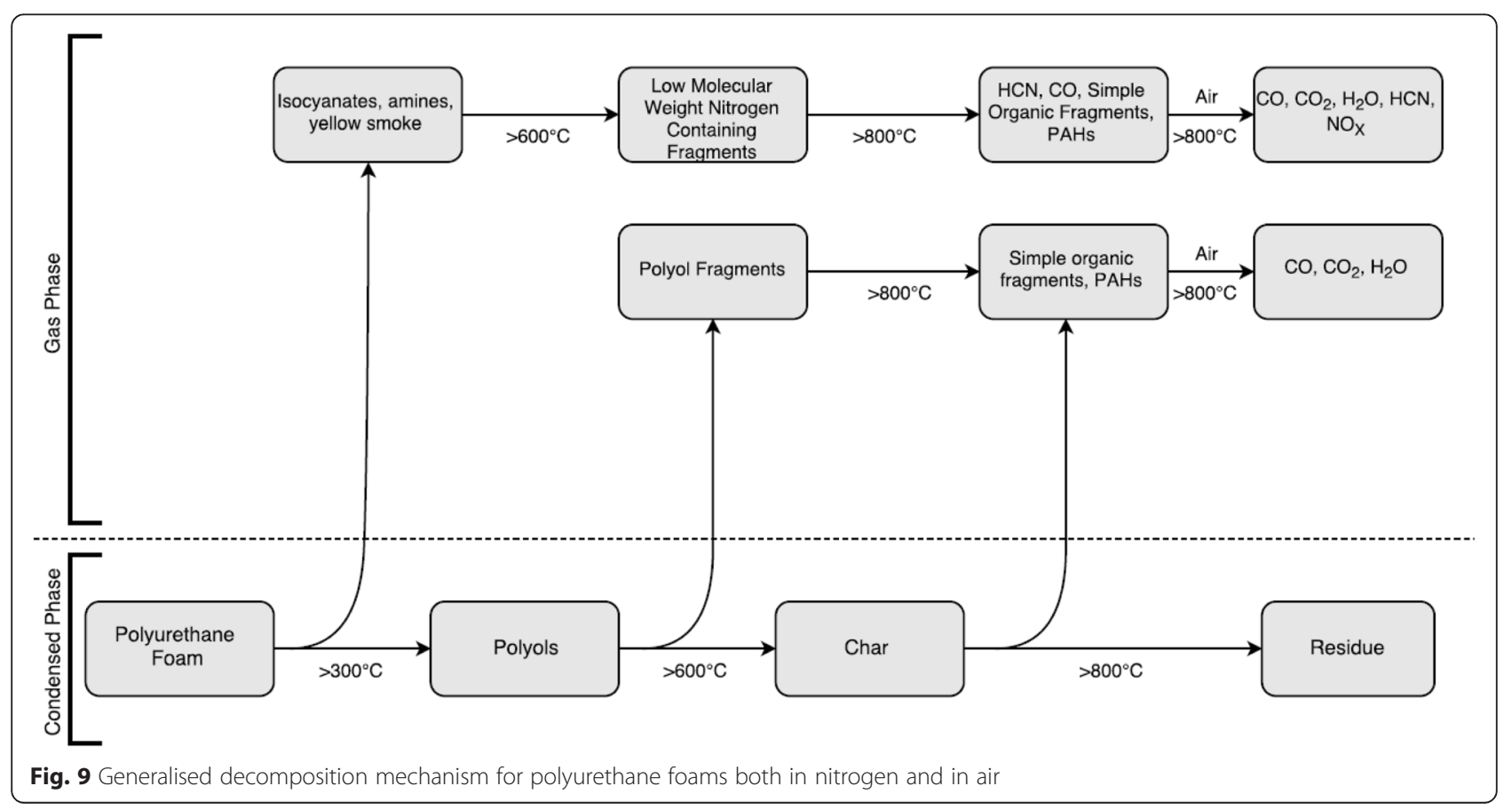


Table 4 The main irritant and asphyxiant components in fire gases and their toxic potencies (in terms of incapacitating; and lethal concentrations) for a 30-min exposure period (ISO 13344 1996: ISO 13571 2012)

\begin{tabular}{lll}
\hline Yield largely independent of fire condition & Yield decreases as ventilation decreases & Yield increases as ventilation decreases \\
\hline $\mathrm{HF}(500 ; 2900 \mathrm{ppm})$ & $\begin{array}{l}\mathrm{CO}_{2}(\sim 7 \% ; \sim 10 \%) \text { also replaces } \\
\mathrm{O}_{2} \text { and } \\
\text { increases respiration rate). }\end{array}$ & CO (1170 ppm; $5700 \mathrm{ppm})$ \\
$\mathrm{HCl}(1000 ; 3800 \mathrm{ppm})$ & $\mathrm{NO}_{2}(170 ; 250 \mathrm{ppm})$ & $\mathrm{HCN}(82 \mathrm{ppm} ; 165 \mathrm{ppm})$ \\
$\mathrm{HBr}(1000 ; 3800 \mathrm{ppm})$ & $\mathrm{SO}_{2}(150 ; 1400 \mathrm{ppm})$ & $\begin{array}{l}\text { Acrolein }(30 \mathrm{ppm} ; 150 \mathrm{ppm}) \\
\end{array}$ \\
& & Formaldehyde (250 ppm; $750 \mathrm{ppm})$ \\
& Aromatics, aldehydes, ketones etc. \\
\hline
\end{tabular}

survival, while other toxicants such as $\mathrm{CO}$ or $\mathrm{HCN}$, will be present in lethal quantities further from the fire where the oxygen depletion would not be considered harmful.

\section{Carbon monoxide}

The toxic effect of carbon monoxide is characterised by a lowered oxygen-delivery capacity of the blood, even when the partial pressure of oxygen and the rate of blood flow are normal. Carbon monoxide binds to the haemoglobin in red blood cells resulting in the formation of carboxyhaemoglobin (COHb), with stability 200 times greater than that of oxyhaemoglobin, impeding the transport of oxygen from the lungs to the cells in the body. This causes deterioration in mental and muscular performance. $\mathrm{CO}$ also combines with myoglobin in the muscle cells, impairing diffusion of oxygen to cardiac and skeletal muscles (Purser 2008b). Over short periods, inhaled CO impairs an individuals ability to escape, causing different effects at different concentrations. At a CO concentration of $10 \mathrm{ppm}$, impairment of judgement and visual perception occur; exposure to 100 ppm causes dizziness, headache, and weariness; loss of consciousness occurs at 250 ppm; and 1000 ppm results in rapid death.

\section{Hydrogen cyanide}

Hydrogen cyanide is approximately 25 times more toxic than carbon monoxide through the formation of the cyanide ion, which is formed by hydrolysis in the blood (Hartzell 1993). Unlike carbon monoxide which remains primarily in the blood (as $\mathrm{COHb}$ ), the cyanide ion is distributed throughout the extra-cellular fluid of tissues and organs (ISO 13571 2007). Two mechanisms have been identified for the toxic effects of cyanide. The first is by combination with the ferric ion in mitochondrial cytochrome oxidase, preventing electron transport in the cytochrome system and inhibiting the use of oxygen by the cells. The second results in a brief stimulation, followed by severe depression, of respiratory frequency, also starving the body of oxygen, and causing convulsions, respiratory arrest and death (Alarie 2002). Whether one or other of these mechanisms predominates, or their interrelationship, remains unclear. $\mathrm{HCN}$ also causes rapid incapacitation, preventing escape, and then, with $\mathrm{CO}$, contributes to death from asphyxiation. One analysis of fire victims' blood showed a trend of declining $\mathrm{COHb}$ and a rise in cyanide concentrations (Anderson et al. 1981), probably because of increased use of nitrogen-containing synthetic polymers. The uptake, distribution, metabolism and excretion of cyanide is much more complex than for $\mathrm{CO}$ and quantifying $\mathrm{CN}^{-}$in fire victims is more expensive and not routinely undertaken. Therefore the contribution of $\mathrm{HCN}$ to fire deaths is difficult to assess, and analysis for $\mathrm{CN}^{-}$is limited to cases where lethal concentrations of $\mathrm{CO}$ are absent.

\section{Irritant gases}

In contrast to the relatively well-defined effects of asphyxiants, the effects of exposure to irritants are more complex. Irritant gases cause pain and breathing difficulties, leading to incapacitation, such that the victim can no longer effect their own escape (ISO 13571 2012). Sensory and upper respiratory tract irritation stimulates the trigeminal and vagus nerve receptors in the eyes, nose, throat and upper respiratory tract causing discomfort, then severe pain. The effects range from tears and reflex blinking of the eyes, pain in the nose, throat and chest, breathholding, coughing, excessive secretion of mucus, to bronchoconstriction and laryngeal spasms (Purser 2008b). At sufficiently high concentrations, or when attached to submicron particles, such as soot, most irritants can penetrate deeper into the lungs, causing pulmonary irritation effects which may cause post-exposure respiratory distress and death, generally occurring from a few hours to several days after exposure, due to pulmonary oedema (flooding of the lungs) (ISO 13571 2007)

\section{Hydrogen halides}

Hydrogen chloride $(\mathrm{HCl})$ and hydrogen bromide $(\mathrm{HBr})$ are strong acids which dissociate entirely in water. Both may be present in fire effluent, for example from PVC or halogenated flame retardants, and since the damage caused by the acidity (the concentration of $\mathrm{H}^{+}$ions $)$is independent of the specific anion $\left(\mathrm{Cl}^{-}\right.$or $\mathrm{Br}^{-}$), the discussion on $\mathrm{HCl}$ is also applicable to $\mathrm{HBr}$. 


\section{Nitrogen oxides}

Nitric oxide (NO) and nitrogen dioxide $\left(\mathrm{NO}_{2}\right)$ are nonflammable gases present in fire effluents. At high concentrations nitric oxide is rapidly oxidised in air to form nitrogen dioxide, however, at the concentrations found in fire gases, most of the nitric oxide remains unoxidised. $\mathrm{Ni}$ trogen dioxide dissolves rapidly in water to form nitric and nitrous acid. At high concentrations these acids can cause pulmonary oedema and death (Paul et al. 2008; Kaplan 1987b). Conversely, nitric oxide gas at low concentrations ( $20 \mathrm{ppm})$ has been used to aid breathing in the treatment of respiratory disorders (Kavanagh \& Pearl 1995).

\section{Isocyanates}

In general, isocyanate (R-NCO) exposure causes irritation to the skin, mucous membranes, eyes and respiratory tract (NIOSH 1989). The most commonly reported adverse health effects after airborne isocyanate exposure is asthma due to sensitisation (Piirilä et al. 2008), where inhaled isocyanates rapidly form conjugates with epithelial lung cell proteins (Wisnewski et al. 1999). Once sensitisation has occurred, even extremely low concentrations of airborne isocyanates can trigger fatal asthma attacks (Henneken et al. 2007).

\section{Quantification of toxic hazards from fire}

The general approach in generating toxic potency data from chemical analysis is to assume additive behaviour of individual toxicants, and to express the concentration of each as its fraction of the lethal concentration for $50 \%$ of the population for a $30 \mathrm{~min}$ exposure (gas$\mathrm{LC}_{50}$ ). Summing these contributions generates a fractional effective dose (FED). An FED equal to one indicates that the sum of concentrations of individual species will be lethal to $50 \%$ of the population over a 30 min exposure. These types of approaches have used existing rat lethality data, as described in ISO 13344 (1996) or more recently, based on the best available estimates of human toxicity thresholds as described in ISO 13571 (2007). An equation has been developed for the estimation of the FED for lethality from the chemical composition of the environment in the physical fire (such as the bench-scale methods described in the following section) model taken from ISO 13344 (1996) and uses gas- $\mathrm{LC}_{50}$ values for lethality to provide reference toxicity data for the individual gases to calculate toxic potency, based on rats exposed for $30 \mathrm{~min}$. The Purser model, presented in equation 1 , uses $\mathrm{V}_{\mathrm{CO}_{2}}$ a multiplication factor for $\mathrm{CO}_{2}$ driven by hyperventilation, therefore increasing the FED contribution from all the toxic species, and incorporates an acidosis factor $\mathrm{A}$ to account for toxicity of $\mathrm{CO}_{2}$ in its own right (ISO 13344 1996).

\section{Equation 1 Purser model}

$$
\begin{aligned}
\mathrm{FED}= & \left\{\frac{[\mathrm{CO}]}{\mathrm{LC}_{50, \mathrm{CO}}}+\frac{[\mathrm{HCN}]}{\mathrm{LC}_{50, \mathrm{HCN}}}+\frac{[\mathrm{AGI}]}{\mathrm{LC}_{50, \mathrm{AGI}}}+\frac{[\mathrm{OI}]}{\mathrm{LC}_{50, \mathrm{OI}}} \ldots\right\} \\
& \times \mathrm{V}_{\mathrm{CO}_{2}}+\mathrm{A}+\frac{21-\left[\mathrm{O}_{2}\right]}{21-5.4} \\
\mathrm{~V}_{\mathrm{CO}_{2}=}= & 1+\frac{\exp \left(0.14\left[\mathrm{CO}_{2}\right]\right)-1}{2}
\end{aligned}
$$

[AGI] is the concentration of inorganic acid gas irritants [OI] is the concentration of organic irritants $\mathrm{A}$ is an acidosis factor equal to $\left[\mathrm{CO}_{2}\right] \times 0.05$

This equation only relates to lethality, or cause of death. However, many people fail to escape from fires because of the incapacitating effect of smoke (obscuring visibility) and its irritant components which cause pain, preventing breathing and escape or reason death occurred. ISO 13571 (2007) considers the four major hazards from fire which may prevent escape (toxic gases, irritant gases, heat and smoke obscuration). Equations 2 and 3 have been taken from ISO 13571 (2007). Equation 2 calculates the FED of the major asphyxiants, $\mathrm{CO}$ and $\mathrm{HCN}$, but without taking oxygen depletion or $\mathrm{CO}_{2}$ driven hyperventilation into account. Equation 3 calculates the Fractional Effective Concentration (FEC) of sensory irritants in the fire effluent which limit escape. Equation 2 represents the generally accepted case that there are only two significant asphyxiant fire gases, $\mathrm{CO}$ and $\mathrm{HCN}$. The FED value is calculated using the exposed dose relationship (concentration-time product, C.t) for CO. The incapacitating C.t product corresponds to $\mathrm{CO}$ at a dose of $35000 \mu \mathrm{L} \mathrm{L} \mathrm{L}^{-1}$ min (approximately equal to $\mathrm{ppm} \mathrm{min}$ ), predicting incapacitation at around $1200 \mathrm{ppm}$ for $30 \mathrm{~min}$ exposure, and an exponential relationship for $\mathrm{HCN}$ (because asphyxiation by $\mathrm{HCN}$ exposure does not fit a linear relationship), predicting incapacitation at around $82 \mathrm{ppm}$ for $30 \mathrm{~min}$ exposure. However, as fires tend to grow exponentially, they do not produce constant concentrations of asphyxiant gases.

Equation 2 FED model from ISO 13571

$$
\mathrm{FED}=\sum_{t_{1}}^{t_{2}} \frac{[\mathrm{CO}]}{35000} \Delta t+\sum_{t_{1}}^{t_{2}} \frac{\exp ([\mathrm{HCN}] / 43)}{220} \Delta t
$$

Equation 3 FEC model from ISO 13571

$$
\begin{aligned}
\mathrm{FEC}= & \frac{[\mathrm{HCl}]}{\mathrm{IC}_{50, \mathrm{HCl}}}+\frac{[\mathrm{HBr}]}{\mathrm{IC}_{50, \mathrm{HBr}}}+\frac{[\mathrm{HF}]}{\mathrm{IC}_{50, \mathrm{HF}}}+\frac{\left[\mathrm{SO}_{2}\right]}{\mathrm{IC}_{50, \mathrm{SO}_{2}}} \\
& +\frac{\left[\mathrm{NO}_{2}\right]}{\mathrm{IC}_{50, \mathrm{NO}_{2}}}+\frac{[\mathrm{acrolein}]}{\mathrm{IC}_{50, \text { acrolein }}}+\frac{[\text { fomaldehyde }]}{\mathrm{IC}_{50, \text { fomaldehyde }}} \\
& +\sum \frac{[\mathrm{irritant}]}{\mathrm{IC}_{50, \text { irritant }}}
\end{aligned}
$$

Equation 3 uses a similar principle to equation 1 to estimate the combined effect of all irritant gases. 
In order to relate the fire effluent toxicity to a "maximum permissible loading", the FED can be related to the mass of material in a unit volume which would cause $50 \%$ lethality for a given fire condition. The fire toxicity of a material can also be expressed as a material-LC $\mathrm{C}_{50}$, which in this case is the specimen mass $M$ of a burning polymeric material which would yield an FED equal to one within a volume of $1 \mathrm{~m}^{3}$. The relation of the FED to the material- $\mathrm{LC}_{50}$ is given in equation 4.

Equation 4 Relation of $L C_{50}$ to FED

$$
\text { material-LC } \mathrm{L}_{50}=\frac{M}{\mathrm{FED} \times V}
$$

Comparing the toxic potencies of different materials, the lower the material- $\mathrm{LC}_{50}$ (the smaller the amount of materials necessary to reach the toxic potency) the more toxic the material is. $\mathrm{LC}_{50}$ values should be referenced to the fire condition under which they were measured.

\section{The equivalence ratio $\phi$}

The relatively high yields of $\mathrm{CO}$ from under-ventilated fires are held responsible for most deaths through inhalation of smoke and toxic gases. However, in the field of combustion toxicity testing, this under-ventilated burning is the most difficult to create using bench-scale apparatus. Research predicting the carbon monoxide evolution from flames of simple hydrocarbons, reviewed by Pitts (1995), has shown the importance of the equivalence ratio $\phi$.

\begin{tabular}{llll}
\hline & & & \\
& & $\begin{array}{l}\text { Typical CO } \\
\text { yield (g per g } \\
\text { of polymer) }\end{array}$ & actual fuel to air ratio \\
$\phi<1$ & fuel lean flames & 0.01 \\
& $\phi=1$ & stoichiometric flames & 0.05 \\
& $\phi>1$ & fuel rich flames & 0.2 \\
\hline
\end{tabular}

An equivalence ratio of 0.5 represents a well-ventilated scenario, typical of an early growing fire, while a ratio of 2 corresponds to the under-ventilated stage responsible for high yields of toxic effluents. When $\phi=1$ the theoretical amount of air is available for complete combustion to carbon dioxide $\left(\mathrm{CO}_{2}\right)$ and water.

The relationship between equivalence ratio and yields of $\mathrm{CO}$ and other products has been studied in detail for a wide range of materials during flaming combustion using two small-scale apparatus designed specifically for this purpose-the ASTM E2058 fire propagation apparatus (Tewarson 2002) and the ISO/TS 19700 tube furnace apparatus (ISO/TS 19700 2013), in conjunction with a series of large-scale experiments used for validation
(Gottuk \& Lattimer 2002; Blomqvist \& Lonnermark 2001; Purser \& Purser 2008a). The findings from these studies demonstrated that yields of different toxic products are highly dependent on equivalence ratio (either positively or negatively correlated), and elemental and molecular composition of the material. To a lesser extent, parameters such as temperature and oxygen concentration also affect the yields of toxic products.

Most fire deaths and injuries actually occur in residential fires, although assessment of fire toxicity is currently focused on areas where escape is restricted, such as aeroplanes, railway carriages, and passenger ships, which include requirements to quantify the fire toxicity of internal components. In most countries, there are no regulations covering the fire toxicity of building components, or for most road vehicles, including goods vehicles in tunnels. In China and Japan, there are specific restrictions on the use of materials with high fire toxicity in high risk applications such as tall buildings, while an increasing number of jurisdictions permit the alternative performance based design approaches to fire safety. Reliable rate of heat release, fire effluent toxicity and smoke generation data are all essential components of such an assessment. The general approach, described in ISO 13571 (2012), is to ensure that the available safe escape time (ASET) before escape routes become obscured by smoke and/or filled with toxic gases, exceeds the required safe escape time (RSET). Various apparatus and protocols for quantifying fire effluent toxicity in different jurisdictions and industries have been critically reviewed (Hull \& Paul 2007).

\section{Bench-scale methods for generating toxic effluents}

Bench-scale methods used for generating toxic effluents from polyurethane foams have met with controversy. Some methods have proved incapable of properly replicating the most toxic under-ventilated fire condition, where the yields of carbon monoxide and hydrogen cyanide are greatest, while other methods have shown good correlation with large scale test data. Bench-scale methods used for generation of toxic fire effluents ideally should be capable of reproducing individual fire stages or combustion conditions, for input into models of combustion toxicity. Full-scale fires simultaneously involve different fire stages in different places, which are changing with time. However, bench-scale methods which allow the combustion conditions to change during the test are much more difficult to relate to full-scale fires, because the duration of each condition is unknown, and the behaviour of fires changes on scale-up. Most benchscale methods have non-constant combustion conditions, such as those in closed chambers exposed to a constant source of heat, including the smoke density chamber (SDC) (ISO 5659-2 2012), and static tube furnace tests, such as the NF X 70-100 (2006). Those 
with constant combustion conditions are more suited to producing data suitable for comparison and modelling: the steady state tube furnace (SSTF) (ISO/TS 19700 2013) has been specifically designed to achieve this. Intermediate between these two approaches are those that can produce quasi-steady combustion conditions, such as the cone calorimeter (ISO 5660-1 2002) with non-standardised controlled atmosphere attachment (CACC), and the fire propagation apparatus (FPA) (ISO 12136 2011). The difficulty of replicating the conditions of fully developed under-ventilated flaming on a bench-scale is caused by several practical problems. $\phi$ depends on the mass loss rate of the specimen and the available air; for most methods one or both are unknown; $\phi$ will be increased by an unknown factor if products are recirculated into the flame zone. Apparatus where $\phi$ changes rapidly allow little time for sampling and measurement of mass loss and effluent composition at a specific value of $\phi$, with resultant errors and uncertainties. Progressive changes in the composition of a static specimen (for example due to char formation) provide additional complexity. In a compartment fire, the reactions of under-ventilated flaming occur in both the flame zone and in the hot upper layer. Only the SSTF has a heated reaction zone which replicates the hot layer. The applied heat flux must be large enough for burning to continue at oxygen concentrations as low as $5 \%$. In some bench-scale apparatus the heat flux is constant, and often insufficient to sustain flaming at such low oxygen concentrations; further, an unknown quantity of fresh air bypasses the fire plume, so the ventilation condition, and hence $\phi$, remains undefined. Some fire models, such as the cone calorimeter, fire propagation apparatus and smoke density chamber use the temperature of the radiant heater to preselect the radiant heat flux, and then check this using a radiant heat flux meter. Others, such as the NF X 70-100, and the ISO/TS 19700 SSTF use the furnace temperature setting to ensure a consistent radiant heat flux. The radiant heat flux in the ISO/TS 19700 apparatus has been measured (Stec et al. 2008) and is $40 \mathrm{~kW} \mathrm{~m}{ }^{-2}$ in the centre of the furnace at $650{ }^{\circ} \mathrm{C}$ and $78 \mathrm{~kW} \mathrm{~m}{ }^{-2}$ at $825^{\circ} \mathrm{C}$. Each method is described briefly in the following section.

\section{The smoke density chamber}

The most widely used fire-test apparatus, stipulated in smoke regulations in most countries of the developed world, is the smoke density chamber as described in ISO 5659-2 2012, and shown schematically in Fig. 10. Its widespread availability has encouraged its adaptation to toxic gas generation and assessment. The standard specifies four test conditions, but fails to link them to particular fire scenarios. The conditions specified are: $25 \mathrm{~kW} \mathrm{~m}{ }^{-2}$ without piloted ignition; $25 \mathrm{~kW} \mathrm{~m}^{-2}$ with

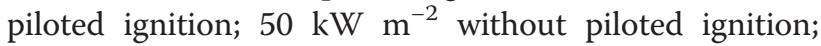

and $50 \mathrm{~kW} \mathrm{~m} \mathrm{~m}^{-2}$ with piloted ignition. The sample is a $75 \times 75 \mathrm{~mm}$ square solid sheet and the standard for smoke measurement states that the results are only valid at the thickness tested (typically 1-4 mm). For a fixed chamber volume $\left(0.51 \mathrm{~m}^{3}\right)$, assuming complete combustion, the sample thickness will dictate the ventilation condition, thus a thin sample will burn under wellventilated conditions with minimum toxic products, while a thicker sample might be expected to produce a high yield of $\mathrm{CO}$ and other products of incomplete combustion. The protocol has been modified as a toxicity test by the mass transport industries, in the aircraft (EN 2826 2011), maritime (Fire Test Procedure Code 2010), and railway tests (CEN/TS 45545-2 2009). Some of these methods attempt to address the transition through the fire stages by monitoring the formation of toxic gases as a function of time, as the oxygen concentration falls, and the fire condition changes from well-ventilated to under-ventilated. However, unlike a real fire, the heat flux remains constant, and so when the oxygen concentration falls, the flame may be extinguished.

The transport industries have adopted the smoke density chamber (SDC) ISO 5659-2 (2012) and ASTM E662, for quantification of toxic product yields (Fire Test Procedure Code 2010; CEN/TS 45545-2 2009) using simple pass/fail chemical detection (e.g. Draeger tubes), conventional or Fourier transform infrared spectroscopy (FTIR) gas analysis, despite significant problems of reproducibility. It has been suggested that the reproducibility problems arise from the single point measurement (the tip of the probe may be in the centre of the plume, below it, or if mixing is more efficient, the upper layer may be recirculated through the flame), or the timing of the effluent sampling may cause instabilities (for example an initial proposal to sample after $8 \mathrm{~min}$ was replaced by a proposal to sample when the smoke density reached its maximum). The revised protocol is based on continuous sampling of the fire effluent.

\section{The controlled atmosphere cone calorimeter (CACC)}

The cone calorimeter (ISO 5660-1 2002) is probably the most widely used apparatus for measurement of flammability properties such as ignitability and heat release rate (Schartel \& Hull 2007). It can be used for testing samples $100 \times 100 \mathrm{~mm}$ and up to $50 \mathrm{~mm}$ thick, in both the horizontal and vertical orientation. The open cone calorimeter replicates the early well-ventilated stage of flaming where a fire would be too small to produce enough toxicants to cause harm except in very small enclosures. However, a non-standard modification of the apparatus has been described, enclosing the fire model in a controlled ventilation chamber, in an attempt to replicate oxygen-depleted conditions. In this modification, the controlled atmosphere cone calorimeter (CACC) 


\section{Gas sampling probe}

\section{Photocell and lamp system}

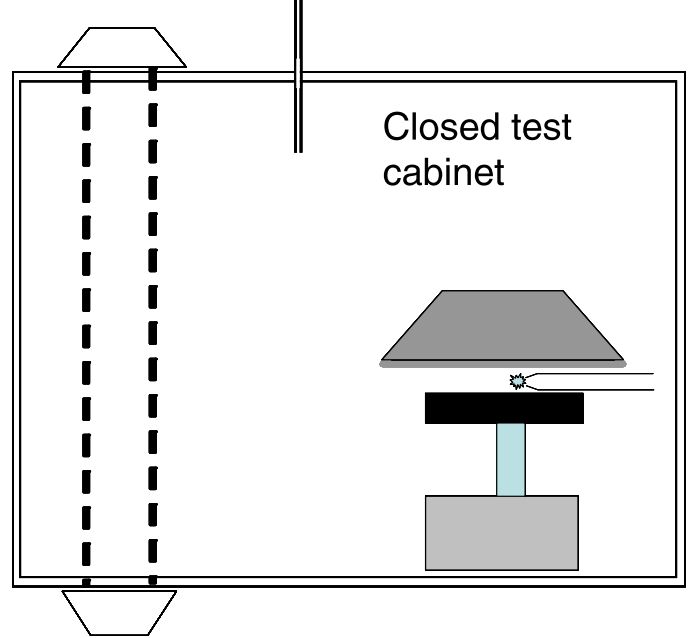

\section{Specimen decomposition system}

Fig. 10 The smoke density chamber (ISO 5659-2) showing a sampling probe for fire smoke toxicity

(Babrauskas et al. 1992), shown in Fig. 11, a conical heater used as a fire model is enclosed in a heat resistant glass chamber $(400 \mathrm{~mm}$ high with $300 \times 300 \mathrm{~mm}$ base) so that the air flow around the specimen may be controlled by diluting the oxygen content with nitrogen. In some cases the effluent continues to burn as it emerges from the chamber, (secondary flaming in Fig. 11) ultimately giving well-ventilated flaming. In others, under reduced oxygen concentrations, the fuel lifts from the surface, but ignition does not occur (Christy et al. 1995). Hietaniemi et al. (1999) used the controlled atmosphere cone calorimeter, but argues correctly, in the authors' opinion, that an instantaneous "effective" global equivalence ratio $\phi_{\text {eff, }}$ should be used, rather than an averaged local equivalence ratio, based on the oxygen supply to the chamber, because, in some experiments, substantial secondary

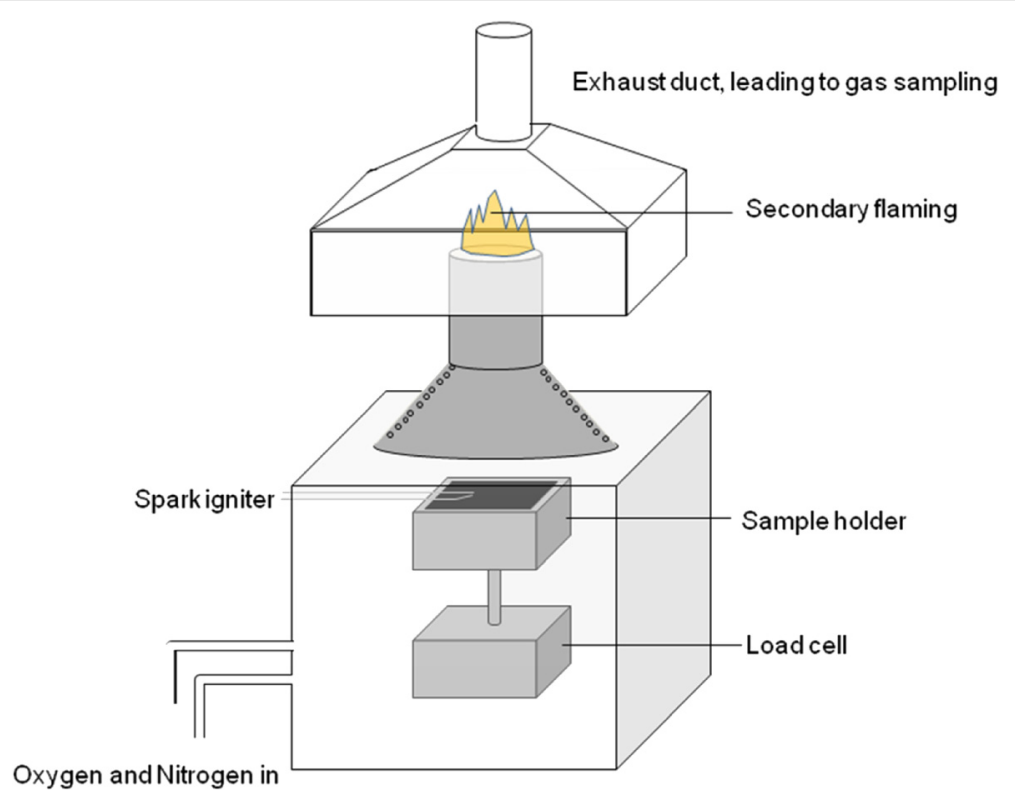

Fig. 11 The controlled atmosphere cone calorimeter 
flaming occurred outside the test chamber, such that the amount of oxygen available to combustion exceeded the amount that was fed to the enclosed chamber.

\section{The steady state tube furnace (SSTF)}

The steady state tube furnace (ISO/TS 19700 2013), shown in Fig. 12, feeds the sample (typically around $25 \mathrm{~g}$ of pellets or granules) into its hot zone at a fixed rate, under a controlled air supply, inside a horizontal silica tube of diameter $48 \mathrm{~mm}$, allowing adequate mixing of fuel and oxidant. It forces combustion by driving the sample into a furnace of increasing heat flux at a fixed rate, so that, by running several tests with the same material with different ventilation conditions, each fire stage can be replicated by steady state burning. The products generated in the flame zone then pass through the heated furnace tube, maintaining a high temperature, as in the upper layer of a compartment fire. The toxic product yields may be quantified from the gas concentrations and mass feed rate during the steady state burn period. It has been designed to generate data for input to fire hazard assessments, using the methodology in ISO 13344 (1996) and ISO 13571 (2012), particularly in relation to the ISO fire stages. The sample is spread evenly in a silica boat over a length of $800 \mathrm{~mm}$ and fed into a tube furnace at a typical rate of $1 \mathrm{~g} \mathrm{~min}^{-1}$ with flowing air at a rate of $2-10 \mathrm{~L} \mathrm{~min}^{-1}$. Secondary air is added in a mixing chamber to give a total gas flow of $50 \mathrm{~L} \mathrm{~min}^{-1}$.

\section{Relationship to full-scale fires}

The yields of $\mathrm{CO}$ and $\mathrm{HCN}$ from five bench-scale methods have been compared to large-scale data under a range of flaming fire conditions (Stec \& Hull 2014). Toxic product yield data from the smoke density chamber (ISO 5659-2 2012), the controlled atmosphere cone calorimeter (based on ISO 5660-1 2002), the fire propagation apparatus (FPA) (ASTM E 2058), the French railway test (NFX) (NF X 70-100 2006), and the steady state tube furnace (SSTF) (ISO/TS 19700 2013) were compared to published large-scale enclosure fire data (from a standard ISO 9705 room) for two polymers, polypropylene (PP) and polyamide 6.6 (PA 6.6). The results from the SSTF and FPA show the best agreement with those from the full and $1 / 3$ scale ISO room for both materials under a range of fire conditions. The CACC and SDC show reasonable agreement for well-ventilated burning, but fail to replicate the more hazardous under-ventilated fire conditions. The NFX generates data intermediate between the well-ventilated and underventilated fire conditions.

\section{Toxic products formed during flaming combustion of polyurethane foams}

In the UK, the rapid rise in fire deaths, in particular those from smoke toxicity, between the late 1950s and the early 1980s has been attributed to the rapid growth in low cost polyurethane foam furniture, with superior comfort and lower cost than the natural fillings that preceded it. The higher flammability of these new furniture products took people by surprise, and has been blamed for an increased number of serious fires and a tripling of fire deaths over 20 years (Fig. 13) (UK Fire Statistics 2013).

Over this period there was a corresponding shift from the main cause of death in fires being attributed to "burns" to being attributed to "inhalation of smoke and toxic gases". Further to this, a similar pattern began to emerge in the injuries of fire victims (Fig. 14) (UK Fire Statistics 2013).

The yields of some of the most toxic gases from unwanted fires (such as $\mathrm{CO}, \mathrm{HCN}$ and some organic irritants) have been demonstrated to be directly related to the combustion conditions (Purser 2002). In the case of flaming combustion, one of the most important factors relating to the toxic product yield is the fuel/air ratio which, as defined earlier, can be expressed as an equivalence ratio $(\phi)$. As the availability of oxygen becomes lower in proportion to the amount of fuel, the yields of certain toxic gases will increase. In

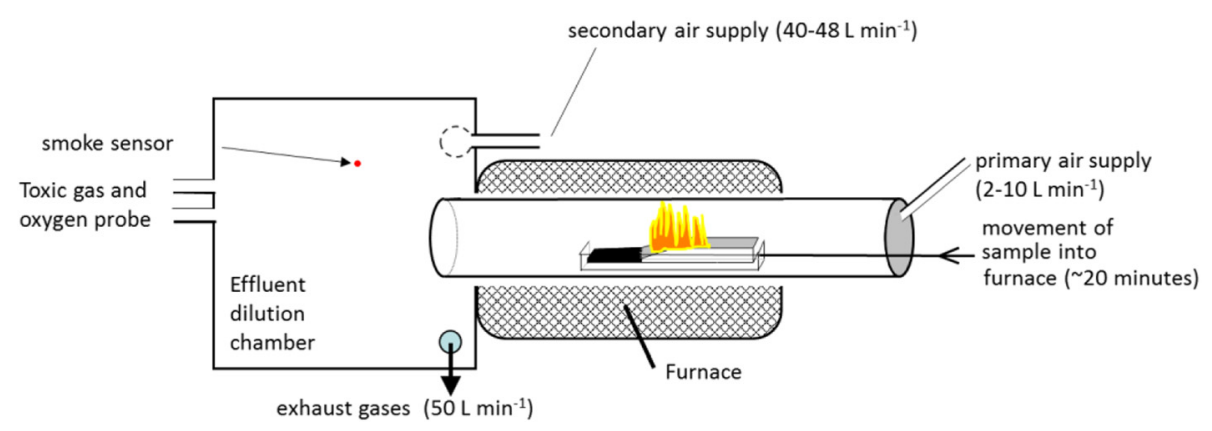

Fig. 12 The Steady state tube furnace apparatus, ISO/TS 19700 


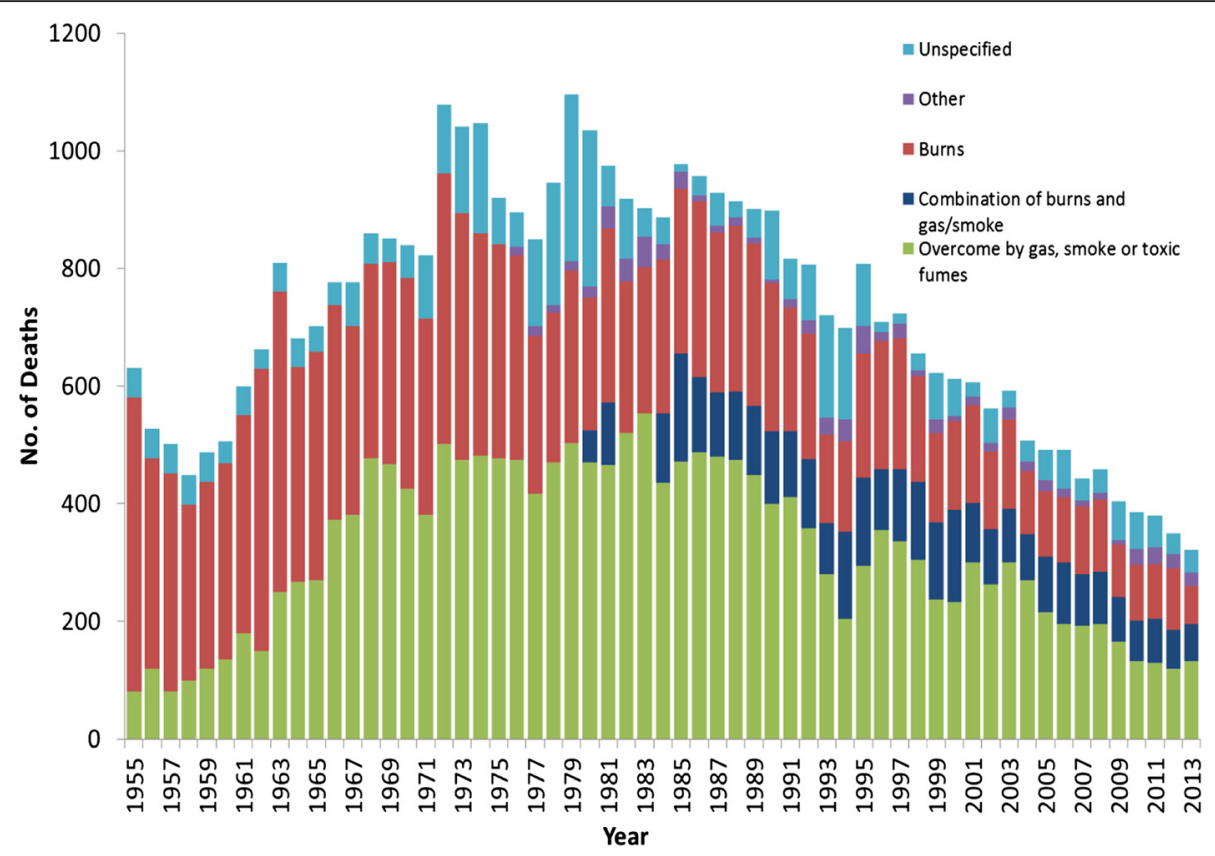

Fig. 13 Causes of UK fire deaths from 1955 to 2013 (UK Fire Statistics 2013)

ventilation controlled fires (such as those occurring in a room, building or other enclosure), the yields of these gases from the flaming combustion of polyurethane foams generally follow the same trend. As a result of this, studies that use ventilation controlled conditions, such as those using the steady state tube furnace (ISO/TS 19700 2013), are more likely to give a realistic representation of these reduced oxygen environment fire conditions.
Stec and Hull (2011) assessed the fire toxicity of building insulation materials using a steady state tube furnace as described in ISO/TS 19700 (2013). The samples tested included both commercial rigid polyurethane foam and polyisocyanurate foam. Under well-ventilated flaming $(\phi<0.8)$, the yields of $\mathrm{CO}_{2}$ and $\mathrm{NO}_{2}$ were at their highest, while the yields of $\mathrm{CO}$ and $\mathrm{HCN}$ were at their lowest. However, as the fire condition became under-ventilated $(\phi>1.5)$, the yields of both $\mathrm{CO}$ and $\mathrm{HCN}$

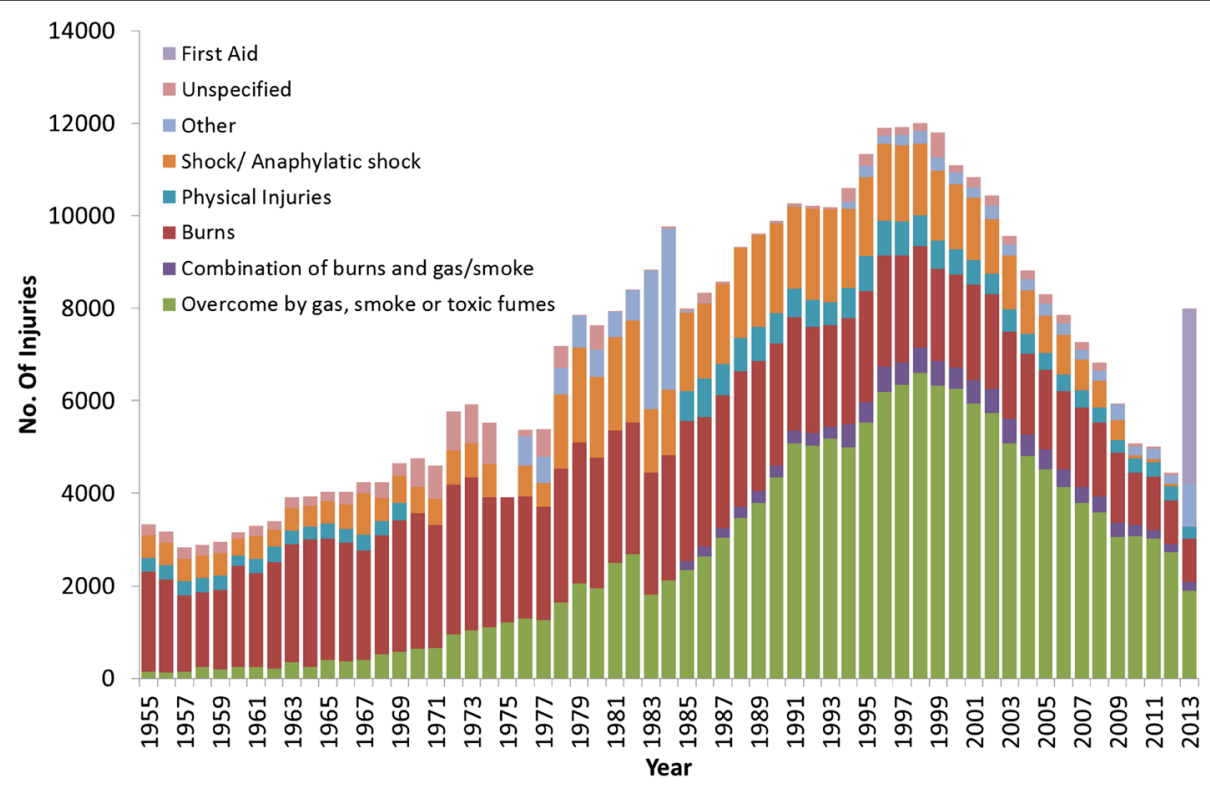

Fig. 14 Non-fatal UK fire injuries requiring hospital treatment, 1955-2013 (UK Fire Statistics 2013) 
Table 5 Toxic product yields the flaming combustion of a rigid polyurethane foam and polyisocyanurate foam (Stec \& Hull 2011)

\begin{tabular}{lllll}
\hline Material & $\begin{array}{l}\text { Furnace } \\
\text { temperature }\left({ }^{\circ} \mathrm{C}\right)\end{array}$ & $\varphi$ & $\begin{array}{l}\mathrm{CO} \\
\text { Yield } / \mathrm{mg} \mathrm{g}^{-1}\end{array}$ & $\begin{array}{l}\mathrm{HCN} \\
\text { Yield } / \mathrm{mg} \mathrm{g}^{-1}\end{array}$ \\
\hline $\begin{array}{l}\text { Rigid Polyurethane } \\
\text { Foam }\end{array}$ & 650 & 0.69 & 60 & 6 \\
& 650 & 1.24 & 220 & 9 \\
& 825 & 2.00 & 240 & 12 \\
Polyisocyanurate & 650 & 0.75 & 80 & 7 \\
Foam & 650 & 1.34 & 220 & 10 \\
& 825 & 1.97 & 225 & 17 \\
\hline
\end{tabular}

increased for both rigid polyurethane and the polyisocyanurate, while the yields of $\mathrm{CO}_{2}$ and $\mathrm{NO}_{2}$ decreased. The yields of $\mathrm{CO}$ and $\mathrm{HCN}$ at varying $\phi$ and temperature are presented in Table 5. For both materials there is a clear increase in yield from the well-ventilated to underventilated conditions. The rigid polyurethane foam produced slightly more $\mathrm{CO}$ than the polyisocyanurate at $\phi$ $\sim 2.0$ (240 $\mathrm{mg} \mathrm{g}^{-1}$ vs $\left.225 \mathrm{mg} \mathrm{g}^{-1}\right)$. The polyisocyanurate, on the other hand, produced slightly more $\mathrm{HCN}$ than the rigid foam ( $17 \mathrm{mg} \mathrm{g}^{-1}$ vs $\left.12 \mathrm{mg} \mathrm{g}^{-1}\right)$. Additionally, the amount of $\mathrm{CO}$ generated for both materials began to taper off at $\phi 1.2-2.0$ as the available oxygen becomes so low that the generation of $\mathrm{CO}$ becomes limited, while the yield of $\mathrm{HCN}$ continues to increase with equivalence ratio and temperature. The authors noted that the yields of $\mathrm{CO}$ during the well-ventilated testing were higher than expected for both materials, and attributed this to the possible presence of gas phase free radical quenchers, such as halogens or phosphorous containing flame retardants, which would reduce the conversion of $\mathrm{CO}$ to $\mathrm{CO}_{2}$ (Schnipper \& Smith-Hansen 1995).

In another investigation, using a steady state tube furnace, Blomqvist et al. (2007) assessed the toxic product yields of a flexible polyurethane foam that was designed for use in hospital mattresses. The test conditions were designed so that the fire conditions met the ISO 19706 (2007) fire type 2 (well-ventilated flaming fire $\phi<0.75$ ) and fire type $3 \mathrm{~b}$ (post-flashover fire in large or open compartments $\phi \sim 2.0)$. The yields of toxic products followed the expected trend of being higher in the under-ventilated conditions. The average well-ventilated yield of $\mathrm{HCN}$ was found to be $4 \mathrm{mg} \mathrm{g}^{-1}$, while it was $9 \mathrm{mg} \mathrm{g}^{-1}$ for under-ventilated conditions. The peak $\mathrm{HCN}$ value reached was $10 \mathrm{mg}$ per $\mathrm{g}^{-1}$ in the underventilated tests. The yield of $\mathrm{CO}$ had a wide range during the under-ventilated tests due to inconsistent flaming of the sample with yields from $100-250 \mathrm{mg} \mathrm{g}^{-1}$. Additionally, NO was detected during the wellventilated tests and $\mathrm{NH}_{3}$ during the under-ventilated tests. This agrees with the fact that oxidation of $\mathrm{NH}_{3}$ and $\mathrm{HCN}$ to $\mathrm{NO}$ (and $\mathrm{NO}_{2}$, although it was not analysed in these experiments) would occur more readily during well-ventilated burning. The authors noted no significant difference in the range of yields of isocyanates detected in either well- or under-ventilated conditions with a range of $1.0-1.6 \mathrm{mg} \mathrm{g}^{-1}$.

Very few authors have assessed the yields of isocyanates produced during the flaming combustion of polyurethane foams and as such there is a limited amount of data available. Investigations by Hertzberg et al. (2003) used a cone calorimeter to assess the yields of amines, aminoisocyanates and isocyanates from the flaming combustion of a flexible polyurethane foam. The average combined yield of isocyanates recovered was $0.869 \mathrm{mg} \mathrm{g}^{-1}$ and the average yield of amines and aminoisocyanates was $0.321 \mathrm{mg} \mathrm{g}^{-1}$. These yields are comparable to that of the results reported by Blomqvist et al. (2007). Additionally, the authors reported a yield of 13-15 mg g $\mathrm{m}^{-1}$ of $\mathrm{CO}, 1.4-1.5 \mathrm{mg} \mathrm{g}^{-1}$ of $\mathrm{HCN}$, and 10 $12 \mathrm{mg} \mathrm{g}^{-1}$ of NO. The authors noted that the yields of the toxicants produced an atmosphere in the tests which fell well below their Immediately Dangerous to Life and Health (IDLH) values. However, the lower yields can be attributed to the fact that the cone calorimeter is a wellventilated scenario, estimated as $\phi \sim 0.7$ (Schartel \& Hull 2007). Taking this into consideration, the reported yields of isocyanates, aminoisocyanates and amines are still relevant, as the results of Blomqvist et al. (2007) suggests that their yields are not heavily dependent on the ventilation conditions and that the yields would likely only increase by a small amount during under-ventilated flaming.

While the link between $\mathrm{CO}$ yield and equivalence ratio is well established, the yield of $\mathrm{HCN}$ in ventilation limited conditions shows more complicated behaviour for polyurethanes. While it is evident that the $\mathrm{HCN}$ yield increases as a fire becomes more under-ventilated, the link between the nitrogen content of the fuel and the yield of $\mathrm{HCN}$ is less clear. In a series of investigations, Purser and Purser (2008a) examined the yields of HCN from a range of materials and the conversion of fuel nitrogen to $\mathrm{HCN}$. A "combustion modified high resilience" flexible polyurethane foam (CMHR-PUF) and a polyisocyanurate (PIR) foam were analysed a steady state tube furnace apparatus. Tests were carried out on the CMHR-PUF at $650{ }^{\circ} \mathrm{C}$ and $850{ }^{\circ} \mathrm{C}$ and at $700{ }^{\circ} \mathrm{C}$ for the PIR in order to achieve steady flaming conditions. Both of the materials showed a clear relationship with the HCN yield increasing with $\phi$. At $650{ }^{\circ} \mathrm{C}$, the yield of $\mathrm{HCN}$ from the CMHR-PUF increased up to $\phi \sim 2.0$ where it reached a peak of $14 \mathrm{mg}$ of $\mathrm{HCN}$ per gram of polymer burned. However, when $\phi>2.0$ the yield of $\mathrm{HCN}$ decreased, falling to $10 \mathrm{mg} \mathrm{g}^{-1}$ at $\phi \sim 2.75$. At $850{ }^{\circ} \mathrm{C}$ the yield of $\mathrm{HCN}$ was higher with $16 \mathrm{mg} \mathrm{g}^{-1}$ at $\phi$ 2.0. The PIR foam produced similar $\mathrm{HCN}$ yields to the CMHR-PUF until $\phi 1.5$, after which it increased more 
rapidly to give a yield of $20 \mathrm{mg} \mathrm{g}^{-1}$ at $\phi \sim 1.75$. This value decreased to $18 \mathrm{mg} \mathrm{g}^{-1}$ at $\phi \sim 2.0$.

Elemental analysis of the polymers showed that the CMHR-FPUR contained $8.22 \%$ nitrogen by weight and the PIR contained $6.15 \%$ nitrogen by weight. Based on this data, the HCN recovery fraction was calculated for both materials. The PIR at $\phi 1.75$ resulted in $15 \%$ of the fuel nitrogen being recovered as $\mathrm{HCN}$. At $\phi \sim 2.0$ the CMHR-FPUR resulted in $8 \%$ and $11 \%$ nitrogen recovered as $\mathrm{HCN}$ for $650{ }^{\circ} \mathrm{C}$ and $850{ }^{\circ} \mathrm{C}$ respectively. The authors acknowledged that the lower nitrogen recovery fraction for the flexible foam could be due to fuel nitrogen being lost as isocyanates, which are known to escape into the effluent plume, while for rigid foams they are more likely to be trapped in the burning solid (Woolley \& Fardell 1977). For the range of materials investigated, the authors also noted that those containing fire retardants (including the CMHR-PUF and PIR) resulted in a higher recovery fraction of fuel $\mathrm{N}$ as HCN. Similarly to the trend reported by Stec and Hull (2011) in well-ventilated conditions, this can be attributed to gas phase free radical quenching in the material by the chlorine present in both the CMHR-PUF and PIR $(2.53 \%$ and $3.56 \%$ chlorine by weight, respectively).

Alongside the experiments performed in the steady state tube furnace, the PIR was also investigated in a half scale ISO 9705 room-corridor test and in a full size ISO 9705 (1993) room. During these tests, the PIR was set up as wall panels covered on two faces with aluminium foil. The cribs used in the ISO 9705 tests were constructed from PIR "sticks" which burned rapidly, albeit with minimal damage to the room. The full size ISO 9705 test resulted in well-ventilated flaming $(\phi 0.26-0.5)$ due to the relatively large volume of air and relatively small sample size. The full-scale test showed good accordance with the SSTF data considering the inherent unreliability of large-scale testing. The half-scale ISO 9705 experiments showed a wider range of ventilation conditions up to $\phi \sim 2.0$. However there was significant scattering of the results with both high and low outliers (26 $\mathrm{mg} \mathrm{g}^{-1}$ at $\phi 1.22$ and $9 \mathrm{mg} \mathrm{g}^{-1}$ at $\phi 1.95$ ). Taking into consideration the issues with repeatability of largescale testing, the authors asserted that the similar trend in $\mathrm{HCN}$ yields supported the good relationship between the tube-furnace and large-scale results.

The increased yield of HCN for the CMHR-FPUR between $650{ }^{\circ} \mathrm{C}$ and $850{ }^{\circ} \mathrm{C}$ is likely due to the increased fragmentation of nitrogenous organic compounds in the flame, similar to the behaviour during non-flaming combustion in air reported by Woolley et al. (1972). Michal (1982) reported a similar trend at a fixed air flow rate. A sample of rigid polyurethane foam was heated in a static tube furnace with an air flow of $50 \mathrm{ml} \mathrm{min}{ }^{-1}$ at a range of temperatures from 600 to $1200{ }^{\circ} \mathrm{C}$ and the yield of $\mathrm{HCN}$ was quantified.
The results showed a $\mathrm{HCN}$ yield of $15.8 \mathrm{mg} \mathrm{g}^{-1}$ at $600{ }^{\circ} \mathrm{C}$. The yield was much lower at $800{ }^{\circ} \mathrm{C}$ with $7.4 \mathrm{mg} \mathrm{g}^{-1}$ but at $1000{ }^{\circ} \mathrm{C}$ and $1200{ }^{\circ} \mathrm{C}$ the yield increased significantly to $33.9 \mathrm{mg} \mathrm{g}^{-1}$ and $48.1 \mathrm{mg} \mathrm{g}^{-1}$ respectively. The specific mass of the polyurethane sample was not provided by the author and the ventilation conditions were not clear as a result of this. The significant increased yields at $1000{ }^{\circ} \mathrm{C}$ and $1200{ }^{\circ} \mathrm{C}$ could also be attributed to pyrolysis of the nitrogenous combustion products into $\mathrm{HCN}$ due to the low air flow rate.

In many studies (such as those by Stec and Hull (2011), Purser and Purser (2008a) and Blomqvist et al. (2007)), the sample is raised to a fixed furnace temperature, which is further increased in the gas phase during flaming combustion. This will result in a $\mathrm{HCN}$ yield related that specific furnace temperature. However, during the combustion of polyurethane foams, the $\mathrm{HCN}$ yield is notably higher when the fire progresses from smouldering to flaming combustion. This was observed by Levin et al. (1985) when a flexible polyurethane foam was first heated at a temperature below its auto-ignition temperature, followed by flaming combustion of the remaining char and residue at a higher temperature. The authors intended to compare the $\mathrm{HCN}$ yields for the non-flaming and flaming combustion of the foam in a smoke chamber apparatus (as described in Levin et al. 1982) to that of a large scale test room. The test room was $2.4 \times 3.0 \times 3.0 \mathrm{~m}$ with a door (dimensions not specified) and a 1 to $2 \mathrm{~kg}$ slab of foam in the centre of the room. Smouldering was forced by an electrically heated resistance wire embedded in the sample and a load cell measured the mass of the sample throughout the experiment. In the smoke chamber, the highest reported yield during flaming combustion was $1.02 \mathrm{mg} \mathrm{g}^{-1}$. In the large scale test room, the sample smouldered for 1.5 to $2 \mathrm{~h}$, resulting in a $\mathrm{HCN}$ yield of $1.03 \mathrm{mg} \mathrm{g}^{-1}$. Once the material ignited, the yield of $\mathrm{HCN}$ increased to $3.8 \mathrm{mg} \mathrm{g}^{-1}$. While the smoke chamber experiment is known to give low $\mathrm{HCN}$ yields, and both scenarios are well-ventilated, the yield of $\mathrm{HCN}$ was almost 4 times as high during flaming combustion if the sample was allowed to smoulder first.

This prompted the authors to perform further studies in order to understand why allowing the foam to smoulder increased the yield of $\mathrm{HCN}$ during flaming combustion. Using a cup furnace with a $200 \mathrm{~L}$ sampling chamber (identical in design to the one used in the smoke chamber experiments), a $3.88 \mathrm{~g}$ sample of foam was heated to just below its ignition temperature $\left(370{ }^{\circ} \mathrm{C}\right)$ which yielded $<1 \mathrm{mg} \mathrm{g}^{-1} \mathrm{HCN}$. In the chamber, $0.23 \mathrm{~g}$ of black char and $0.04 \mathrm{~g}$ of yellow oil were recovered. When the black char was burned at $600{ }^{\circ} \mathrm{C}$, it yielded $14.95 \mathrm{mg}$ of $\mathrm{HCN}$ (65 mg per gram of char) and the yellow oil yielded $21 \mathrm{mg}$ per gram of oil. Elemental analysis of the polymer 
and the char showed that $80 \%$ of the nitrogen in the polymer was lost when heated at $370{ }^{\circ} \mathrm{C}$, but only $0.6 \%$ was recovered as $\mathrm{HCN}$ when burned at $600{ }^{\circ} \mathrm{C}$. However, while the char produced when the polymer was heated at $370{ }^{\circ} \mathrm{C}$ contained only $20 \%$ of the total nitrogen from the polymer, $40 \%$ of that ( $8 \%$ of the total nitrogen in the polymer) was recovered as $\mathrm{HCN}$ when the char was burned at $600{ }^{\circ} \mathrm{C}$. This suggests that the nitrogen in the char will more readily form $\mathrm{HCN}$, even when the flaming is well-ventilated. The amount of nitrogen recovered from the char $(8 \%)$ at $600{ }^{\circ} \mathrm{C}$ is of a similar order to the results reported by Purser and Purser (2008a) in the steady state tube furnace suggesting that the amount of nitrogen in the polyurethane foam converted into $\mathrm{HCN}$ when the material is allowed to smoulder first before flaming is similar to that of steady under-ventilated flaming. In a report from the same laboratory, Braun et al. (1990) also reported increased $\mathrm{HCN}$ yields when the sample was allowed to smoulder before flaming in similar apparatus as above. In a real fire, involving cycles of growth and decay of flaming combustion, the resulting yields of $\mathrm{HCN}$ from the combustion of polyurethane foams are likely to be higher than predicted in some bench-scale methods as a result of this two-step decomposition mechanism.

The widespread use of flexible polyurethane foams in furniture and other upholstery, where they are usually covered in some kind of fabric has prompted some authors to investigate the effects of covering the foam on the yield of toxic products. Levin et al. (1986) investigated the toxicity of flexible polyurethane foam and a polyester fabric both separately and together. Using a smoke chamber set up for animal exposure experiments (as described in Levin et al. 1982), the authors exposed male Fisher 344 rats in a $200 \mathrm{~L}$ exposure chamber to the fire effluent from the flaming and non-flaming combustion of both materials. The reported yields were extremely low for both $\mathrm{CO}$ and $\mathrm{HCN}$, as the NBS smoke chamber apparatus is a well-ventilated fire scenario reported to give low HCN yields (Table 6). Flaming combustion of the polyurethane foam did not cause any animal deaths, however the non-flaming combustion resulted in deaths post-exposure. The authors noted that in both the flaming and non-flaming combustion of the polyurethane foam, the concentrations of toxicants did not reach high enough concentrations to predict deaths. The polyester fabric produced $92-93 \mathrm{mg} \mathrm{g}^{-1}$ of $\mathrm{CO}$ when burned with very little difference in the flaming or non-flaming conditions. This was enough to cause deaths both during and post-exposure. When tested with the polyester covering the polyurethane, the yield of HCN during flaming combustion was higher than that of just the polyurethane foam on its own. However, the yield of $\mathrm{CO}$ was lower in both the non-flaming and flaming combustion. The overall toxicity of the combined materials was higher, and the average concentrations of the gases throughout the tests were consistently higher than that of the individual materials in both flaming and non-flaming conditions. The authors noted that the total concentrations of $\mathrm{CO}$ and $\mathrm{HCN}$ during flaming combustion were greater than the sum of those from the individual materials. It is difficult to draw more general conclusion from this work because the fuel-to-air ratio was not quantified, and the degree of mixing of fresh air and fire effluent, in the exposure chamber, is unknown. However, it does suggest that yield of toxic products is effected by covering the foam with another material during flaming combustion.

Similarly, Busker et al. (1999) tested both rigid and flexible polyurethane foams using a bespoke smoke chamber apparatus to assess the toxicity of the flaming combustion products of the materials to rats. The samples were heated at $800{ }^{\circ} \mathrm{C}$ in a static tube furnace, with the effluent being cooled to $<50{ }^{\circ} \mathrm{C}$ before entering an exposure unit. The rigid polyurethane foam yielded $\sim 55 \mathrm{mg} \mathrm{g}^{-1} \mathrm{CO}$ and $\sim 0.5 \mathrm{mg} \mathrm{g}^{-1}$ of $\mathrm{HCN}$. The flexible foam produced $\sim 175 \mathrm{mg} \mathrm{g}^{-1}$ of $\mathrm{CO}$ and $5 \mathrm{mg} \mathrm{g}^{-1}$ of $\mathrm{HCN}$. The authors also noted that the presence of aldehydes was detected during the flaming combustion of the flexible foam, albeit in extremely low yields. Based on the temperature of the test, the yields of $\mathrm{HCN}$ are extremely low when compared with the $\mathrm{CO}$ yields. The authors did not

Table 6 Concentrations of $\mathrm{CO}$ and HCN from flexible polyurethane foam, polyester fabric and polyester fabric on polyurethane foam (Levin et al. 1986)

\begin{tabular}{|c|c|c|c|c|c|}
\hline \multirow{2}{*}{$\begin{array}{l}\text { Flaming/non-flaming } \\
\text { and temperature }\end{array}$} & \multirow[t]{2}{*}{ Material } & \multicolumn{2}{|l|}{$\mathrm{CO}$} & \multicolumn{2}{|l|}{$\mathrm{HCN}$} \\
\hline & & Concentration/ppm & Yield/mg g ${ }^{-1}$ & Concentration/ppm & Yield/mg g ${ }^{-1}$ \\
\hline Non-flaming & Polyurethane Foam & 740 & 22.8 & 9 & 0.3 \\
\hline \multirow[t]{2}{*}{$374-377^{\circ} \mathrm{C}$} & Polyester Fabric & 2910 & 93 & - & - \\
\hline & Polyester Fabric on Polyurethane Foam & 1390 & 33.28 & 5 & 0.12 \\
\hline Flaming & Polyurethane Foam & 840 & 26.0 & 27 & 1.515 \\
\hline \multirow[t]{2}{*}{$523-527^{\circ} \mathrm{C}$} & Polyester Fabric & 2990 & 92.2 & - & - \\
\hline & Polyester Fabric on Polyurethane Foam & 3070 & 75.72 & 63 & 1.87 \\
\hline
\end{tabular}


specify which analytical methods were used in the quantification of the fire gases, only that they were sampled via a sampling bag.

Several authors have investigated the relationship between bench-scale test data and large-scale test data using polyurethane foams. Babrauskas et al. (1991a) compared a number of test methods. The authors tested a rigid polyurethane foam using a NBS cup furnace (as described in Levin et al. 1982), a developmental method (SwRI/NIST method) which used a radiant heater on the sample which lead into a $200 \mathrm{~L}$ exposure chamber, a cone calorimeter (ISO 5660 2002), a furniture calorimeter (as described in Babrauskas et al. 1982), and a three-compartment large scale test. The three-compartment test consisted of a $2.4 \times 3.7 \times 2.4 \mathrm{~m}$ burn room, a $2.4 \times 4.6 \times 2.4 \mathrm{~m}$ corridor and a $2.4 \times 3.7 \times 2.4 \mathrm{~m}$ target room where samples would be taken. The three compartments were connected by doors and the target room contained an open vent. Although the authors intended for the bench scale test methods and the large scale test to represent postflashover room fires, the tests resulted in $\mathrm{CO}$ and $\mathrm{HCN}$ yields that suggested the combustion conditions were not under-ventilated (Table 7). The test method that produced toxic product yields associated with under-ventilated flaming was the NBS cup furnace toxicity method, which yielded $180-210 \mathrm{mg} \mathrm{g}^{-1}$ of $\mathrm{CO}$ and $16-20 \mathrm{mg} \mathrm{g}^{-1}$. This is unusual as this test method is usually well-ventilated and the results are not similar to reports of other authors (such as Levin et al. 1985 and Levin et al. 1986).

A more recent assessment by Marsh and Gann (2013) tested a flexible polyurethane foam with a cotton polyester cover in a range of test methods including the radiant heat apparatus (NFPA 269 2012), the ISO 5659-2 (2012) smoke density chamber, a controlled atmosphere cone calorimeter (ASTM E 1354) and the steady state tube furnace (ISO/TS 19700 2013). The authors presented a large set of data for all of the test methods, including a range of test conditions, air flow rates, oxygen concentration, and mass loadings. The reported yields for the tests performed can be found in Table 8. The radiant heat apparatus, smoke chamber and controlled atmosphere cone calorimeter produced much lower $\mathrm{CO}$ yields than would be expected for under-ventilated flaming. The steady state tube furnace produced a $\mathrm{CO}$ yield that was closer to what would be expected for under- ventilated conditions. The authors made this assertion based on the yield of average $\mathrm{CO}$ from post-flashover fires being $200 \pm 9 \mathrm{mg} \mathrm{g}^{-1}$. HCN analysis was performed using infrared (IR) spectroscopy using a short pathlength gas cell, which is a questionable method for the quantification of $\mathrm{HCN}$ due to its poor IR absorption, high potential for interferences and a poor limit of detection. This resulted in the reported $\mathrm{HCN}$ yields for the under-ventilated conditions being lower than expected in all of the tests. Taking this into consideration, the steady state tube furnace and the controlled atmosphere cone calorimeter both produced the highest yields of $\mathrm{HCN}$ in under-ventilated conditions.

The authors acknowledged that further investigation of the steady state tube furnace was warranted as in some of the testing they suspected an instrumental error, since they were unable to account for roughly two-thirds of the total carbon from the sample and detected unusually low levels of $\mathrm{CO}_{2}$ during the under-ventilated tests. While there were some problems, the data does show that the yields of toxicants from the polyurethane foam were generally most representative of postflashover conditions in the test methods that were designed for ventilation controlled conditions, such as the steady state tube furnace and the controlled atmosphere cone calorimeter.

As polyurethane foams have very low thermal inertia, application of heat or a small flame can be enough to ignite them. In order to reduce the ignitability, and to a less extent the surface spread of flame and peak heat release rate, fire retardants are commonly added to commercial polyurethane foams in order to meet specific regulatory demands. A comprehensive review of fire retardants and their use in polyurethane foams was published by Singh and Jain (2009). The review refers to a publication by Babrauskas et al. (1991b) wherein polyurethane containing a phosphate fire retardant caused immediate death of all of the animals. Early work by Voorhees (1975) identified what they described as 'extreme toxicity' of the combustion products of a phosphate fire retarded polyurethane foam. Voorhees suggested that the compound was a bicyclic phosphate compound and noted grand mal seizures followed by death in rats with a loading as low as $4 \%$ by weight of the fire retardant. Analysis of the compound, trimethylol propane phosphate (TMPP), by Kimmerle (1976) found it to have a

Table 7 Comparison of yields of CO and HCN for a series of tests (Babrauskas et al. 1991a)

\begin{tabular}{|c|c|c|c|}
\hline Test method & Test conditions & CO Yield/mg g ${ }^{-1}$ & $\mathrm{HCN}$ Yield/mg g ${ }^{-1}$ \\
\hline NBS Cup Furnace Method & $550^{\circ} \mathrm{C}$ & $180-210$ & $16-20$ \\
\hline SwRI/NIST Method & $50 \mathrm{~kW} \mathrm{~m}^{-2}$ & $80-120$ & $1.9-4.4$ \\
\hline Cone Calorimeter Method & Range for $35-75 \mathrm{~kW} \mathrm{~m}^{-2}$ & $42-80$ & $4-5$ \\
\hline Furniture Calorimeter & $330 \times 330 \times 254 \mathrm{~mm}$ crib, $1.0 \mathrm{~kg}$ & 80 & $\mathrm{~N} / \mathrm{a}$ \\
\hline Three-compartment Room Test & See description in text & $100-140$ & $5-11$ \\
\hline
\end{tabular}


Table 8 Yields of CO and HCN from a range of test methods (Marsh \& Gann 2013)

\begin{tabular}{|c|c|c|c|c|c|}
\hline \multirow{2}{*}{$\begin{array}{l}\text { Test type } \\
\text { Radiant Furnace }\end{array}$} & \multicolumn{3}{|l|}{ Test variables } & \multirow[t]{2}{*}{ 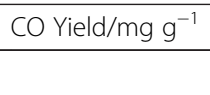 } & \multirow[t]{2}{*}{$\mathrm{HCN}$ Yield/mg g ${ }^{-1}$} \\
\hline & \multicolumn{3}{|l|}{ Initial Oxygen \% } & & \\
\hline & \multicolumn{3}{|l|}{21} & 28 & $<3.0$ \\
\hline & \multicolumn{3}{|l|}{17} & 36 & 1.0 \\
\hline \multirow[t]{4}{*}{ Smoke Density Chamber } & \multicolumn{2}{|l|}{ Irradiance/kW m ${ }^{-2}$} & Pilot & & \\
\hline & \multicolumn{2}{|l|}{50} & Unpiloted & 19 & 3.4 \\
\hline & \multicolumn{2}{|l|}{50} & Piloted & 66 & 1.0 \\
\hline & \multicolumn{2}{|l|}{25} & Piloted & 43 & 6 \\
\hline \multirow[t]{3}{*}{ Steady State Tube Furnace } & \multicolumn{3}{|l|}{ Temperature } & & \\
\hline & \multicolumn{3}{|c|}{$650^{\circ} \mathrm{C}$ (well-ventilated) } & 26 & $<3.0$ \\
\hline & \multicolumn{3}{|c|}{$825^{\circ} \mathrm{C}$ (under-ventilated) } & 143 & 8.8 \\
\hline \multirow[t]{10}{*}{ Controlled Atmosphere Cone Calorimeter } & Irradiance $/ \mathrm{kW} \mathrm{m}^{-2}$ & Air Flow/L s ${ }^{-1}$ & Initial Oxygen \% & & \\
\hline & \multirow[t]{3}{*}{50} & \multirow[t]{3}{*}{25} & 21 & 27 & 3.7 \\
\hline & & & 18 & 35 & 7.7 \\
\hline & & & 16 & 44 & 12.5 \\
\hline & \multirow[t]{3}{*}{50} & \multirow[t]{3}{*}{12.5} & 21 & 24 & 3.6 \\
\hline & & & 16 & 35 & 9.6 \\
\hline & & & 14 & 33 & 3.9 \\
\hline & \multirow[t]{3}{*}{25} & \multirow[t]{3}{*}{25} & 21 & 24 & - \\
\hline & & & 18 & 29 & - \\
\hline & & & 16 & 29 & - \\
\hline
\end{tabular}

high acute toxicity when tested on rats. The formation of the toxicant in question was the result of an unusual reaction of the polyol in the foam, trimethylol propane, with the phosphate fire retardant in the gas phase.

Paabo and Levin (1987) reviewed the literature of the toxic product generated by the combustion of rigid polyurethane foams. The review suggested that the addition of fire retardants did not appear increase the overall combustion toxicity of polyurethane foams. However, this did not take into consideration the incapacitating effects of the release of irritant gases. A more recent review, by Levchik and Weil (2004), assessed the decomposition, combustion and fire-retardancy of polyurethanes. The author acknowledged that there is a range of contradictory results available in the literature regarding their fire toxicity. It is likely that the fire toxicity of fire retarded polyurethane materials is largely dependent on the specific fire retardant present. For example, Levin and coworkers reported that melamine-treated flexible polyurethane foam generated 6 times more HCN than an equal amount of non-melamine treated foam. However, the presence of $\mathrm{Cu}_{2} \mathrm{O}$ reduced the $\mathrm{HCN}$ generated by the flexible polyurethane foam by $70-90 \%$ at low temperatures. The authors associated this with the effects of the $\mathrm{Cu}_{2} \mathrm{O}$ catalytically oxidising the $\mathrm{HCN}$ into $\mathrm{N}_{2}, \mathrm{CO}_{2}, \mathrm{H}_{2} \mathrm{O}$ and a small amount of nitrogen oxides.
Since then, Blais and Carpenter (2015) investigated a flexible polyurethane foam with and without a chloro phosphate (tris-dichloro-propyl phosphate TDCPP) fire retardant using a smoke box (ISO 5659-2 2012) to assess the toxicity. The authors asserted that fire retarding flexible polyurethane foam did not increase its acute or chronic toxicity when compared to non-fire retarded flexible foam. They also asserted that the toxicity of the fire retarded foam was less than or equal to wood on a mass/mass basis and that wood contributes significantly more to residential fires in terms of fire smoke toxicity. However, due to the poor reproducibility of smoke chamber experiments, the tendency for it to give very low $\mathrm{HCN}$ yields, and the fact that the experiment is well-ventilated, the reported toxicity is likely much lower than in a real fire situation. In a letter to the editor of the journal, Barbrauskas et al. (2015) questioned their methodology and noted that the authors did not address the release of $\mathrm{HCl}$ and its contribution to the acute fire toxicity of the fire retarded foam.

Historically, material- $\mathrm{LC}_{50}$ data has been reported directly based on animal lethality testing, however due to the declining use of animal testing in fire toxicity assessment, calculations based on standard lethality data (such as ISO 13344 1996) are more commonly used. As the toxic product yields of polyurethane foams are directly related to the ventilation conditions, so is the materials 
Table 9 Fire Toxicity of polyurethane foam and polyisocyanurate foam in a range of conditions, represented as a material- $L C_{50}$ (Stec \& Hull 2011)

\begin{tabular}{lllc}
\hline Material & Fire conditions & $\varphi$ & Material-LC \\
\hline Polyurethane Foam & Smouldering & - & 337.2 \\
& Well-ventilated & 0.69 & 15.7 \\
& Under-ventilated & 1.24 & 10.3 \\
& Under-ventilated & 2.00 & 11.4 \\
Polyisocyanurate Foam & Smouldering & - & 498.4 \\
& Well-ventilated & 0.75 & 16.5 \\
& Under-ventilated & 1.34 & 10.7 \\
& Under-ventilated & 1.97 & 8.3 \\
\hline
\end{tabular}

$\mathrm{LC}_{50}$ value. Stec and Hull (2011) presented material$\mathrm{LC}_{50}$ data for rigid polyurethane foam and polyisocyanurate foam, calculated using rat lethality data from ISO 13344 (1996). A summary of these results can be found in Table 9. The overall toxicity of the polyisocyanurate foam shows a clear increase as the fire became more under-ventilated, while the rigid polyurethane foam showed a slight decrease at $\phi 1.24-2.00$. This slight decrease is probably within the limits of experimental error, as it does not follow the general trend shown by most materials. Using the methodology in ISO 13344, the authors also calculated the fractional effective dose (FED) of the individual toxicants sampled. The FED is expressed as the sum of contributions to toxicity from individual species and normalised to $1 \mathrm{~g}$ of fuel in $200 \mathrm{~L}$ fire effluent, as used in BS 6853 (1999). The calculations showed that, for both the rigid polyurethane and the polyisocyanurate, hydrogen cyanide is the major toxicant in smouldering, well-ventilated and under-ventilated flaming. The authors acknowledged that they did not include isocyanates in their calculations.

Neviaser and Gann (2004) compiled the toxic potency data for a range of materials including a number of fire retarded and non-fire retarded polyurethane foams. The authors compiled toxicological data from a range of primary online databases and also requests were made to collect unpublished data that were not publically available. From this, the library of data was sorted into categories of combustion/pyrolysis conditions, material/ product, type of test animal and toxicological endpoint. The authors noted that a large number of the data available relating to the test conditions were vague or completely undefined. In particular, reports that used non-standard tube furnace apparatus lacked sufficient information about the conditions of the experiment and as such were not included. The data was presented as material- $\mathrm{LC}_{50}$ values for $30 \mathrm{~min}$ exposures with 14-day post-exposure of test animals and can be found in Tables 10, 11 and 12.
Table $10 L_{50}$ values for well-ventilated flaming combustion (Neviaser \& Gann 2004)

\begin{tabular}{|c|c|c|}
\hline Material & Reference & $\begin{array}{l}\text { Material-LC } \mathrm{C}_{50} \\
(30 \mathrm{~min}+14 \\
\text { day post }) / \mathrm{g} \mathrm{m}^{-3}\end{array}$ \\
\hline \multicolumn{3}{|l|}{ Flexible Polyurethane Foam } \\
\hline NFR FPU \#12 & Levin et al 1983a & 40.0 \\
\hline FR FPU \#11 & Levin et al 1983a & 40.0 \\
\hline No details provided & Babrauskas et al 1991b & 52.0 \\
\hline Melamine type foam & Babrauskas et al 1991b & 12.5 \\
\hline $\begin{array}{l}\text { Melamine type foam } \\
\text { with vinyl fabric }\end{array}$ & Babrauskas et al 1991b & 26.0 \\
\hline FR FPU \#14 & Levin et al 1983a & 27.8 \\
\hline FR foam- $22.3 \mathrm{~kg} \mathrm{~m}^{-3}$ & Braun et al 1990 & 26.0 \\
\hline FR GM-23 & Farrar et al 1979 & 34.5 \\
\hline FR GM-27 & Farrar et al 1979 & 33.1 \\
\hline NFR FPU \#13 & Levin et al 1986 & 40.0 \\
\hline NFR foam $22.3 \mathrm{~kg} / \mathrm{m}^{-3}$ & Braun et al 1990 & 40.0 \\
\hline NFR GM-21 & Levin et al 1983b & 38.0 \\
\hline NFR GM-21 & Levin et al 1983b & 49.5 \\
\hline NFR GM-21 & Levin et al 1983b & 40.0 \\
\hline NFR GM-21 & Farrar et al 1979 & 43.2 \\
\hline NFR GM-25 & Farrar et al 1979 & 37.5 \\
\hline NFR Foam & Farrar \& Galster 1980 & 43.2 \\
\hline $\begin{array}{l}\text { NFR Upholstered Chairs } \\
\text { with FPUR, cover fabric } \\
\text { and steel frame. Foam } \\
\text { density: } 25 \mathrm{~kg} \mathrm{~m}^{-3}\end{array}$ & Barbrauskas et al. 1988 & 35.0 \\
\hline \multicolumn{3}{|l|}{ Rigid Polyurethane Foam } \\
\hline $\begin{array}{l}\text { NFR Foam, } 25 \mathrm{~mm} \text { thick, } \\
96 \mathrm{~kg} \mathrm{~m}^{-3}\end{array}$ & Babrauskas et al 1991a & 11.0 \\
\hline FR GM-31 & Farrar et al 1979 & 14.2 \\
\hline No details provided & Babrauskas et al 1991b & 22.0 \\
\hline NFR GM-30 & Levin et al 1983b & 38.4 \\
\hline NFR GM-30 & Levin et al 1983b & 13.3 \\
\hline NFR GM-30 & Levin et al 1983b & 11.3 \\
\hline NFR isocyanurate, GM-41 & Farrar et al 1979 & 11.4 \\
\hline NFR isocyanurate, GM-43 & Farrar et al 1979 & 5.8 \\
\hline NFR GM-29 & Farrar et al 1979 & 11.2 \\
\hline NFR GM-35 & Farrar et al 1979 & 12.1 \\
\hline NFR GM-37 & Farrar et al 1979 & 10.9 \\
\hline NFR GM-39, sprayed & Farrar et al 1979 & 16.6 \\
\hline
\end{tabular}

During flaming combustion, many fire retarded flexible polyurethane foams showed similar or slightly higher toxic potency than the non-fire retarded foams in both well-ventilated and under-ventilated conditions. While limited data were available regarding the flaming combustion of rigid polyurethane foams, the results were of a similar scale to those presented by Stec and Hull (2011). While the data presented is a useful compilation of toxic potency data from the available literature before 2004, the report does not take into consideration the 
Table $11 \mathrm{LC}_{50}$ values for under-ventilated flaming combustion (Neviaser \& Gann 2004)

\begin{tabular}{|c|c|c|}
\hline Material & Reference & $\begin{array}{l}\text { Material-LC } 50 \\
(30 \mathrm{~min}+14 \\
\text { day post }) / \\
\mathrm{g} \mathrm{m}^{-3}\end{array}$ \\
\hline \multicolumn{3}{|c|}{ Flexible polyurethane foam } \\
\hline No details provided & $\begin{array}{l}\text { Babrauskas et al. } \\
1991 b\end{array}$ & 18.0 \\
\hline $\begin{array}{l}\text { FR upholstered chairs } \\
\text { with FPUR padding, } \\
\text { cover fabric and a } \\
\text { steel frame }\end{array}$ & $\begin{array}{l}\text { Barbrauskas et al. } \\
1988\end{array}$ & 23.0 \\
\hline Melamine type foam & $\begin{array}{l}\text { Babrauskas et al. } \\
1991 \text { b }\end{array}$ & 8.0 \\
\hline $\begin{array}{l}\text { Melamine type foam } \\
\text { with vinyl fabric }\end{array}$ & $\begin{array}{l}\text { Babrauskas et al. } \\
1991 b\end{array}$ & 15.0 \\
\hline $\begin{array}{l}\text { Melamine type foam } \\
\text { with vinyl fabric }\end{array}$ & $\begin{array}{l}\text { Babrauskas et al. } \\
\text { 1991b }\end{array}$ & 15.0 \\
\hline \multicolumn{3}{|l|}{ Rigid polyurethane foam } \\
\hline No details provided & $\begin{array}{l}\text { Babrauskas et al. } \\
1991 b\end{array}$ & 14.0 \\
\hline
\end{tabular}

conclusions of individual authors, the exact specifics of the test condition, and the validity of the results. The data also does not specify the fire retardants used. Overall, the report provides access to a large pool of data organised into a material-LC $\mathrm{L}_{50}$ and also helps demonstrate that the large majority of data available is for wellventilated tests.

\section{Conclusions}

The non-flaming decomposition of polyurethanes in air or nitrogen can be summarised effectively using a generalised mechanism based on the available literature (Fig. 9). The mechanisms of decomposition are well understood and the decomposition products of both rigid and flexible polyurethane foams are very similar at high temperatures. At lower temperatures, decomposition differs, depending on the composition and physical properties of the polymer, although clear trends can be identified. A detailed understanding of the thermal decomposition chemistry of polyurethane foams is necessary in order to relate the toxicants generated during both flaming and non-flaming combustion of the polymer to its structure.

$\mathrm{CO}$ and $\mathrm{HCN}$ are the main asphyxiants produced during the combustion of polyurethanes and there have been a large number of studies published regarding their yields. Isocyanates should be considered when assessing the fire toxicity of polyurethane foams, due to their acute irritating effects and chronic effects associated with exposure. However, there is very little literature available regarding the yields of isocyanates produced by the combustion of polyurethane foams.
Table $12 L C_{50}$ values for oxidative pyrolysis (Neviaser \& Gann 2004)

\begin{tabular}{|c|c|c|}
\hline Material & Reference & $\begin{array}{l}\text { Material-LC } \\
(30 \mathrm{~min}+14 \\
\text { day post)/ } \\
\mathrm{g} \mathrm{m}^{-3}\end{array}$ \\
\hline \multicolumn{3}{|l|}{ Flexible polyurethane foam } \\
\hline NFR FPU \#12 & Levin et al 1983a & 37.8 \\
\hline NFR FPU \#13 & Levin et al 1986 & 37.0 \\
\hline NFR Foam: $22.3 \mathrm{~kg} \mathrm{~m}^{-3}$ & Braun et al 1990 & 33.0 \\
\hline NFR GM-21 & Levin et al 1983b & 27.8 \\
\hline NFR GM-21 & Levin et al 1983b & 40.0 \\
\hline NFR GM-21 & Levin et al 1983b & 26.6 \\
\hline FR FPU \#11 & Levin et al 1983a & 17.2 \\
\hline FR FPU \#14 & Levin et al 1983a & 40.0 \\
\hline FR Foam: $22.3 \mathrm{~kg} \mathrm{~m}^{-3}$ & Braun et al 1990 & 23.0 \\
\hline FR GM-23 & Farrar et al 1979 & 12.6 \\
\hline FR GM-27 & Farrar et al 1979 & 30.5 \\
\hline NFR GM-21 & Farrar et al 1979 & 13.4 \\
\hline NFR GM-25 & Farrar et al 1979 & 36.9 \\
\hline NFR Foam & Farrar \& Galster 1980 & 14.3 \\
\hline NFR GM-21: 2 PCF & Anderson et al 1983 & 34.7 \\
\hline \multicolumn{3}{|l|}{ Rigid polyurethane foam } \\
\hline NFR GM-30 & Levin et al 1983b & 34.0 \\
\hline NFR GM-30 & Levin et al 1983b & 39.6 \\
\hline NFR GM-30 & Levin et al 1983b & 35.1 \\
\hline FR GM-31 & Farrar et al 1979 & 40.0 \\
\hline NFR Isocyanurate; GM-41 & Farrar et al 1979 & 8.0 \\
\hline NFR isocyanurate; GM-43 & Farrar et al 1979 & 5.0 \\
\hline NFR GM-29 & Farrar et al 1979 & 40.0 \\
\hline NFR GM-35 & Farrar et al 1979 & 36.7 \\
\hline NFR GM-37 & Farrar et al 1979 & 36.7 \\
\hline NFR GM-39; sprayed & Farrar et al 1979 & 10.9 \\
\hline
\end{tabular}

During flaming combustion of polyurethane foams, the yield of toxicants can be directly related to the fuel/ air ratio, expressed as an equivalence ratio $(\phi)$. This results in relatively high yields of $\mathrm{CO}$ and $\mathrm{HCN}$ during under-ventilated flaming and relatively low yields during well-ventilated flaming. Test methods, such as the steady state tube furnace (ISO/TS 19700) and the controlled atmosphere cone calorimeter (ASTM E 1354), facilitate ventilated controlled conditions which give yields of $\mathrm{CO}$ and $\mathrm{HCN}$ comparable to those observed in underventilated post-flashover compartment fires. The average $\mathrm{CO}$ yield expected from under-ventilated flaming is $\sim 200 \mathrm{mg} \mathrm{g}^{-1}$ for polyurethane materials.

$\mathrm{HCN}$, in particular, contributes significantly to the overall fire toxicity of polyurethane foams. Around 10$15 \%$ of the nitrogen in the polymer can be converted 
into $\mathrm{HCN}$ with some being released in isocyanates, aminoisocyanates and amines in the fire effluent. Additionally, $\mathrm{HCN}$ yields in both flaming and non-flaming conditions increases with temperature. This can be explained by the fragmentation of nitrogen containing organics in the flame and in the effluent, as suggested by studies of the inert-atmosphere decomposition of polyurethane materials. $\mathrm{HCN}$ yields reported in underventilated conditions vary depending on the composition of the material; with flexible foams producing less than rigid foams and polyisocyanurates producing the most overall.

The overall toxicity of polyurethane materials followed a similar trend to their HCN yields; with flexible foams generally being the least toxic, rigid foams being slightly more toxic and polyisocyanurate foams being the most toxic.

There is some contradiction the literature as to the effect fire retardants have on the overall toxicity of polyurethane foams. A large majority of the literature indicates that the addition of fire retardants does not increase toxicity of polyurethane foams. This is due to the large range of available fire retardants found in polyurethane foams, which suggests that the toxicity will likely follow the general trends in the literature for all materials regarding fire retardants. Fire retardants, such as gas-phase free radical quenchers, have been reported to increase the yields of $\mathrm{CO}$ in well-ventilated conditions by preventing the oxidation of $\mathrm{CO}$ to $\mathrm{CO}_{2}$. Other fire retardants such as melamine are reported to significantly increase the $\mathrm{HCN}$ yield of polyurethane foams. The presence of $\mathrm{Cu}_{2} \mathrm{O}$ drastically decreased the yield of $\mathrm{HCN}$ in polyurethane foams at lower temperatures, but had little effect at high temperatures.

As the global usage of polyurethane foams is expected to continue to increase yearly, it is important that the fire community have a clear understanding of the fire toxicity of polyurethane foams and the reasons why they produce significant amounts of toxic gases during combustion. Since $\mathrm{HCN}$ is a major contributor to the fire toxicity of polyurethane foams, the mechanisms by which they decompose are vital in understanding why they produce large-quantities of $\mathrm{HCN}$ during underventilated burning.

\footnotetext{
Abbreviations

2,4-TDI: 2,4-Toluene diisocyanate; 2,6-TDI: 2,6-Toluene diiscoyanate; ASET: available safe escape time; CACC: controlled atmosphere cone calorimeter; CMHR-PUF: combustion modified high resilience polyurethane foam; COHb: carboxyhaemoglobin; DAT: diaminotoluene; FED: fractional effective dose; FPA: fire propatation apparatus; HDI: hexamethylene diisocyanate; IPDI: isophorone diisocyanate; MDI: methylene diphenyl diisocyanate; NDI: 1,5-naphthalene diisocyanate; PAHs: polycyclic aromatic hydrocarbons; PIR: polyisocyanurate; PPM: parts per million; RSET: required safe escape time; SDC: smoke density chamber; TGA: thermogravimetric analysis; TMPP: trimethylol propane phosphate.
}

\section{Competing interests}

The authors declare that they have no competing interests.

\section{Authors' contributions}

STM wrote the manuscript and produced all of the images used in figures. $\mathrm{TRH}$ wrote the fire toxicity section of the manuscript. Both authors read and approved the manuscript.

\section{Acknowledgements}

The authors would like to thank Dr. Linda Bengtstrom for her contribution regarding the toxicity of isocyanates.

\section{Funding}

STM would like to acknowledge the University of Central Lancashire for provision of a studentship.

Received: 3 February 2016 Accepted: 31 March 2016

Published online: 21 April 2016

\section{References}

Alarie Y (2002) Toxicity of Fire Smoke. Critical Reviews in Toxicology 32(4):259

Allan D, Daly J, Liggat JJ (2013) Thermal volatilisation analysis of TDI-based flexible polyurethane foam. Polymer Degradation and Stability 98:535-541

Anderson RA, Watson AA, Harland WA (1981) Fire Deaths in the Glasgow Area: I General Considerations and Pathology. Med Sci Law 21:60

Anderson RC, Croce PA, Feeley FG, Sakura JD (1983) Study to assess the feasibility of incorporating combustion toxicity requirements into building materials and furnishing codes of New York State: Final report, vol I, II, III, Arthur D. Little, Inc. Report, Reference 88712, May 1983.

Andersson B, Markert F, Holmstedt G (2005) Combustion products generated by hetero-organic fuels on four different fire test scales. Fire Safety Journal 40:439-465

Aneja A (2002) Chapter 2, Structure-property Relationships of Flexible Polyurethane Foams, PhD. thesis, Virginia Tech, p6-40

ASTM E 1354 Standard Test Method for Heat and Visible Smoke Release Rates for Materials and Products Using an Oxygen Consumption Calorimeter

ASTM E 662 Standard Test Method for Specific Optical Density of Smoke Generated by Solid Materials

Avar G, Meier WU, Casselmann H, Achten D (2012) Polymer Science: A Comprehensive Reference, Polymer Science: A Comprehensive Reference, 10, p411-441.

Babrauskas V, Lawson JR, Walton WD, Twilley WH (1982) Upholstered Furniture Heat Release Rates Measured with a Furniture Calorimeter. NBSIR 82-2604. National Bureau of Standards, Washington D.C.

Babrauskas V, Harris RH, Braun E, Levin BC, Paabo M, Gann RG (1991a) The role of bench-scale test data in assessing real-scale fire toxicity, Technical Note 1284, National Bureau of Standards and. Technology, Gaithersburg MD

Babrauskas V, Levin BC, Gann R, Paabo M, Harris RH, Peacock RD, Yusa S (1991b) Toxic potency measurement for fire hazard analysis, special publication 827, National Institute of Standards and Technology. Gaithersberg, MD

Babrauskas V, Twilley WH, Janssens M, Yusa S (1992) Cone calorimeter for controlled-atmosphere studies. Fire and Materials 16:p37-43

Barbrauskas V, Harris RH, Gann RG, Levin BC, Lee BT, Peakcock RD, Paabo M, Twilley W, Yoklavich MF, Clark HM (1988) Fire hazard comparison of fireretarded and non-fire-retarded products, Special Publication 749. National Bureau of Standards, Gaithersburg MD

Barbrauskas V, Singla V, Lucas D, Rich D (2015) Letter to the Editor- Questions about the conclusions in Blais and Carpenter 2013. Fire Technology 51:p213-217

Blais M, Carpenter K (2015) Flexible Polyurethane Foams: A comparative measurement of toxic vapors and other toxic emissions in controlled combustion environments of foams with and without fire retardants. Fire Technology 51:p3-18

Blomqvist P, Lonnermark A (2001) Characterization of the combustion products in large-scale fire tests: comparison of three experimental configurations. Fire and Materials 25:p71-81

Blomqvist P, Hertzberg T, Tuovinen H, Arrhenius K, Rosell L (2007) Detailed determination of smoke gas contents using a small-scale controlled equivalence ratio tube furnace method. Fire and Materials 31:p495-521

Bott B, Firth JG, Jones TA (1969) Evolution of toxic gases from heated plastics. Brit Polym J 1:p203-204

Braun E, Gann RG, Levin BC, Paabo M (1990) Combustion product toxic potency measurements: comparison of a small scale test and "real-world" fires. Journal of Fire Sciences 8:p63-79 
BS 6853 (1999) Code of practise for fire precautions in the design and construction of passenger carrying trains

Busker RW, Hammer AH, Kuijpers WC, Poot CAJ, Bergers WWA, Bruijnzeel, PLB (1999) Toxicity testing of combustion products of polyurethane and polyvinylchloride. TNO Report. PML 1998-A97. TNO Prins Maurits Laboratory, The Netherlands. p 1-30.

CEN/TS 45545-2 (2009) Railway applications - Fire protection on railway vehicles Part 2: Requirements for fire behaviour of materials and components

Chambers J, Jiricny J, Reese CB (1981) The Thermal Decomposition of Polyurethanes and Polyisocyanurates. Fire and Materials 5(4):p133-141

Christy M, Petrella R, Penkala J (1995) Controlled-atmosphere cone calorimeter. Fire and Polymers II: Materials and Tests for Hazard Prevention 599:p498-517

Chun BH, Li X, Im EJ, Lee KH, Kim SH (2007) Comparison of Pyrolysis Kinetics between Rigid and Flexible Polyurethanes. J Ind Eng Chem 13(7):p1188-1194

EN 2826. (2011) Aerospace series - Burning behaviour of non-metallic materials under the influence of radiating heat and flames - Determination of gas components in the smoke; ABD 0031 Fire-Smoke-Toxicity (FST) Test Specification (Airbus Industries); Boeing BSS 7239, Test method for toxic gas generation by materials on combustion.

Farrar DG, Galster WA (1980) Biological end-points for the assessment of the toxicity of products of combustion of material. Journal of Fire and Materials 4:p50-58

Farrar DG, Hartzell GE, Blank TL, Galster WA (1979) Development of a protocol for the assessment of the toxicity of combustion products resulting from the burning of cellular plastics, University of Utah Report, UTEC 79/130; RP-75-2-1 Renewal, RP-77-U-5. City, Salt Lake

UK Fire Statistics 2013 (and preceding years) - United Kingdom

Fire Test Procedure Code (2010) Maritime Safety Committee, (MSC 87/26/Add.3) Annex 34, Part 2 Smoke and Toxicity Test. International Maritime Organisation, London

Garrido MA, Font R (2015) Pyrolysis and combustion study of flexible polyurethane foam. Journal of Analytical and Applied pyrolysis 113:p202-215

Gharehbagh A, Ahmadi Z (2012) Chapter 6: Polyurethane Flexible Foam Fire Behaviour, Polyurethane. In: Fahima Z, Eram S (eds), InTech. p 102-120. ISBN 978-953-51-0726-2

Gottuk DT, Lattimer BY (2002) SFPE Handbook of Fire Protection Engineering, 3rd ed. (P.J. DiNenno et al., eds.). National Fire Protection Association, Quincy, MA, pp 54-82

Guo X, Wanga L, Zhanga L, Lia S, Hao J (2014) Nitrogenous emissions from the catalytic pyrolysis of waste rigid polyurethane foam. Journal of Analytical and Applied pyrolysis 108:p143-150

Hartzell G (1993) Overview of Combustion Toxicology. Toxicology 115:7

Henneken H, Vogel M, Karst U (2007) Determination of airborne isocyanates. Anal Bioanal Chem 387:p219-236

Herrington R, Hock K (1998) Flexible Polyurethane Foams, 2nd edn. Chem Co., Dow

Hertzberg T, Blomqvist P, Dalene M, Skarping G (2003) Particles and Isocyanates from Fires. SP Swedish National Testing and Research Institute, Borås

Hietaniemi J, Kallonen R, Mikkola E (1999) Burning characteristics of selected substances: Production of heat, smoke and chemical species. Fire and Materials 23:p171-185

Hull TR, Paul KT (2007) Bench-scale assessment of combustion toxicity-A critical analysis of current protocols. Fire Safety Journal 42:p340-365

ISO 12136 (2011) Reaction to fire tests - Measurement of material properties using a fire propagation apparatus

ISO 13344 (1996) Estimation of lethal toxic potency of fire effluents

ISO 13571 (2012) Life-threatening components of fire-Guidelines for the estimation of time available for escape using fire data

ISO/TS 19700 (2013) Controlled equivalence ratio method for the determination of hazardous components of fire effluents - the steady state tube furnace.

ISO 19706 (2011) Guidelines for assessing the fire threat to people.

ISO 5659-2 (2012) Plastics - Smoke generation - Part 2: Determination of optical density by a single-chamber test

ISO 5660-1 (2002) Fire tests - Reaction to fire - Part 1: Rate of heat release from building products (cone calorimeter method)

ISO 9705 (1993) Fire tests - Full-scale room tests for surface products

Kaplan HL (1987b) Effects of irritant gases on avoidance/escape performance and respiratory response of the baboon. Toxicology 47:165-170

Kaplan HL, Grand AF, Hartzell GE (1984a) Toxicity and the smoke problem. Fire Safety Journal 7:p11

Kavanagh BP, Pearl RG (1995) Inhaled nitric oxide in anesthesia and critical care medicine. Int Anesthesiol Clin 33:181
Kimmerle G (1976) Toxicity of Combustion Products with Particular Reference to Polyurethane. Ann occup Hyg 19:269-273

Levchik SV, Weil ED (2004) Thermal Decomposition, combustion and fireretardancy of polyurethanes - a review of the recent literature. Polymer International 53:p1585-1610

Levin BC, Fowell AJ, Birky MM, Paabo M, Stolte A, Malek D (1982) Further development of a test method for the assessment of the acute inhalation toxicity of combustion products. NBSIR 82-2532. National Bureau of Standards, Washington D.C.

Levin BC, Paabo M, Fultz ML, Bailey C, Yin W, Harris SE (1983a) Acute inhalation toxicological evaluation of combustion products from fire-retarded and nonfire retarded flexible polyurethane foam and polyester. NBSIR 83-2719. National Bureau of Standards, Gaithersburg, MD

Levin BC, Paabo M, Birky MM (1983b) Interlaboratory evaluation of the 1980 version of the national bureau of standards test method for assessing the acute inhalation toxicity of combustion products, NBSIR 83-2678, National Bureau of Standards, Gaithersberg, MD

Levin BC, Paabo M, Fultz ML, Bailey CS (1985) Generation of Hydrogen Cyanide from Flexible Polyurethane Foam Decomposed under Different Combustion Conditions. Fire and Materials 9:p125-134

Levin BC, Paabo M, Bailey CS, Harris SE (1986) Toxicity of the combustion products from a flexible polyurethane foam and a polyester fabric evaluated separately and together by the NBS Toxicity Test Method. Fire Safety Science - Proceedings of the First International Symposium, p1111-1122

Markets and Markets report (2011) Methylene Diphenyl Diisocyanate (MDI), Toluene Diisocyanate (TDI) and Polyurethane Market (2011 - 2016): Markets and Markets CH 1596, July 2011

Marsh ND, Gann RG (2013) Smoke Component Yields from Bench-Scale Fire Tests: 4. Comparison with Room Fire Results, NIST Technical Note 1763, National Institute of Standards and Technology, Gaithersburg, MD

Michal J (1982) Determination of Hydrogen Cyanide in Thermal Degradation Products of Polymeric Materials. Fire and Materials 6:p13-15

Neviaser JL, Gann RG (2004) Evaluation of Toxic Potency values for Smoke from Products and Materials. Fire Technology 40:p117-199

NFPA 269 (2012) Standard test method for developing toxic potency data for use in fire hazard modelling

NFX 70 100-1:2006 Fire Tests - Analysis Of Gaseous Effluents - Part 1: Methods For Analysing Gases Stemming From Thermal Degradation

NIOSH (1989) A summaryof health hazard evaluations: Isocyanates, 1989 to 2002

Paabo M, Levin BC (1987) A review of the literature on the gaseous products and toxicity generated from the pyrolysis and combustion of rigid polyurethane foams. Fire and Materials 11:p1-29

Paul KT, Hull TR, Lebek K, Stec AA (2008) Fire smoke toxicity: The effect of nitrogen oxides. Fire Safety Journal 43:243-251

Piirilä PL, Meuronen A, Majuri ML, Luukkonen R, Mäntylä T, Wolff HJ (2008) Inflammation and functional outcome in diisocyanate-induced asthma after cessation of exposure. Allergy 63:p583-591

Pitts WM (1995) The global equivalence ratio concept and the formation mechanisms of carbon monoxide in enclosure fires. Prog Energy Combust Sci 21:197-237

Purser DA (2002) Toxicity Assessment of Combustion Products, The SPFE Handbook of Fire Protection Engineering 3rd Edition, Edited by DiNenno, P.J. National Fire Protection Association, Quincy, pp 2-83

Purser DA (2007) The application of exposure concentration and dose to evaluation of effects of irritants as components of fire hazard. Interflam Conference Proceedings. Interscience Publications, London

Purser DA (2008b) Chapter 2: SFPE Handbook of Fire Protection Engineering (Ed. PJ. DiNenno) Fourth Edition. National Fire Protection Association, Quincy MA, USA, pp 2-96

Purser DA, Purser JA (2008a) HCN yields and fate of fuel nitrogen for materials under different combustion conditions in the ISO 19700 tube furnace. Fire Safety Science - Proceedings of the ninth international symposium. p 1117-11128. International Association for Fire Safety Science

Ravey M, Pearce EM (1997) Flexible Polyurethane foam. I. Thermal Decomposition of Polyether-based, Water-blown Commerical type of Flexible Polyurethane Foam. Journal of Applied Polymer Science 63:p47-74

Rein G, Lautenberger C, Fernandez-Pell AC (2006) Application of Genetic Alogorithms and Thermogravimetry to Determine the Kinetics of Polyurethane Foam in Smoldering Combustion. Combustion and Flame 146(1-2):p95-108

Rogaume T, Bustamante-Valencia L, Guillaume E, Richard F, Luche J, Rein G, Torero $\lrcorner$ (2011) Development of the Thermal Decomposition Mechanism of 
Polyether Polyurethane Foam Using Both Condensed and Gas-Phase Release Data. Combustion Science and Technology 183(7):p627-644

Saunders JH (1959) the Reactions of Isocyanates and Isocyanate Derivatives at Elevated Temperatures. Rubber Chemistry and Technology 32(2):p337-345

Schartel B, Hull TR (2007) Development of fire-retarded materials - interpretation of cone calorimeter data. Fire and Materials 31:p327-354

Schnipper L, Smith-Hansen ES (1995) Reduced combustion efficiency of chlorinated compounds, resulting in higher yields of carbon monoxide. Fire and Materials 19:p61-64

Shufen L, Zhi J, Kaijun Y, Shuqin Y, Chow WK (2006) Studies on the Thermal Behavior of Polyurethanes. Polymer-Plastics Technology and Engineering 45:p95-108

Singh H, Jain AK (2009) Ignition, Combustion, Toxicity, and Fire Retardancy of Polyurethane Foams: A Comprehensive Review. Journal of Applied Polymer Science 111:p1115-1143

Stec AA, Hull TR (2011) Assessment of the fire toxicity of building insulation materials. Energy and Buildings 43:p498-506

Stec AA, Hull TR (2014) Fire Toxicity Assessment: Comparison of Asphyxiant Yields from Laboratory and Large Scale Flaming Fires. Fire Safety Science 11:p404-418

Stec AA, Hull TR, Lebek K (2008) Characterisation of the steady state tube furnace (ISO TS 19700) for fire toxicity assessment. Polymer Degradation and Stability 93:p2058-2065

Tewarson A (2002) SFPE Handbook of Fire Protection Engineering, 3rd ed. P.J. DiNenno et al. eds. National Fire Protection Association, 82, p 161

Vilar WD (2002) Chemistry and Technology of Polyurethanes - Chapter 1. Vilar Consultoria Técnica Ltda, Rio de Janeiro

Voorhees J (1975) Extreme Toxicity from Combustion Products of Fire-Retarded Polyurethane Foam. Science 187:p742-744

Wisnewski AV, Lemus R, Karol MH, Redlich CA (1999) Isocyanate-conjugated human lung epithelial cell proteins: A link between exposure and asthma? J Allergy Clin Immunol 104:p341-347

Woolley WD, Fardell PJ (1977) The prediction of combustion products. Fire Res 1:p11-21

Woolley WD, Fardell PJ, Buckland IG (1975) The Thermal Decomposition Products of Rigid Polyurethane. Foams Under Laboratory Conditions, Fire Research Note, No 1039

Woolley WD, Wadley Al, Field P (1972) Studies of the thermal decomposition of flexible polyurethane foams in air. Fire Research Notes 951:p1-17

\section{Submit your manuscript to a SpringerOpen ${ }^{\circ}$ journal and benefit from:}

- Convenient online submission

- Rigorous peer review

- Immediate publication on acceptance

- Open access: articles freely available online

- High visibility within the field

- Retaining the copyright to your article 